\title{
Mechanism of Cobalamin-Mediated Reductive Dehalogenation of Chloroethylenes
}

\author{
Ji, Li; Wang, Chenchen; Ji, Shujing; Kepp, Kasper Planeta; Paneth, Piotr
}

Published in:

A C S Catalysis

Link to article, DOI:

10.1021/acscatal.7b00540

Publication date:

2017

Document Version

Peer reviewed version

Link back to DTU Orbit

Citation $(A P A)$ :

Ji, L., Wang, C., Ji, S., Kepp, K. P., \& Paneth, P. (2017). Mechanism of Cobalamin-Mediated Reductive Dehalogenation of Chloroethylenes. A C S Catalysis, 7(8), 5294-5307. https://doi.org/10.1021/acscatal.7b00540

\section{General rights}

Copyright and moral rights for the publications made accessible in the public portal are retained by the authors and/or other copyright owners and it is a condition of accessing publications that users recognise and abide by the legal requirements associated with these rights.

- Users may download and print one copy of any publication from the public portal for the purpose of private study or research.

- You may not further distribute the material or use it for any profit-making activity or commercial gain

- You may freely distribute the URL identifying the publication in the public portal 
3

4

5

6

8

10

\title{
Mechanism of Cobalamin-Mediated Reductive
}

\section{Dehalogenation of Chloroethylenes}

\author{
Li Ji ${ }^{*, 1}$, Chenchen Wang $^{1}$, Shujing $\mathrm{Ji}^{1}$, Kasper P. Kepp ${ }^{*, 2}$, Piotr Paneth ${ }^{*, 3}$
}

\footnotetext{
${ }^{1}$ College of Environmental and Resource Sciences, Zhejiang University, Yuhangtang Road 866,
}

Hangzhou 310058, China

${ }^{2}$ DTU Chemistry, Technical University of Denmark, Building 206, Kgs. Lyngby, DK-2800,

Denmark

${ }^{3}$ Institute of Applied Radiation Chemistry, Faculty of Chemistry, Lodz University of

Technology, Zeromskiego 116, 90-924 Lodz, Poland 


\section{Abstract}

2 Reductive dehalogenation involving cobalamin has been provend to be a promising strategy for

3 decontamination of polluted environments. However, cob(I)alamin can act both as a strong

4 reductant and a powerful nucleophile, and thus several competing dehalogenation pathways may

5 be involved. This work uses experimentally calibrated density functional theory on realistic

6 cobalamin models to resolve controversies of cobalamin-mediated reduction of chloroethylenes

7 by exploring mechanisms of electron transfer, nucleophilic substitution, and nucleophilic addition.

8 The computational results provides molecular-level insight into the competing pathways for

9 chloroethylenes reacting with cob(I)alamin: the computed ratios of inner-sphere to outer-sphere

10 pathways for perchloroethylene and trichloroethylene are 17:1 and 3.5:1 respectively in accord

11 with corresponding experimental ratios of $>10: 1$ and $>2.3: 1$, while the computed outer-sphere

12 pathway for other less-chlorinated ethylenes is hampered by high barriers ( $>25 \mathrm{kcal} / \mathrm{mol}$ ). Thus

13 a new mechanistic picture has beenis obtained:-that The highly-chlorinated ethylenes primarily

14 react via an inner-sphere nucleophilic-substitution pathway, while-whereas the less_-chlorinated

15 ethylenes mainly react through an inner-sphere nucleophilic-addition pathway. Especially, the

16 母Quantitative comparison of standard reduction potentials between-of the formed chlorinated -

17 cobalamin and cob(II)alamin/cob(I)alamin couple can be used to distinguish whether the- inner-

18 sphere pathway eould-can proceed or not, and the-linear free energy relationships have been

19 developed to predict the reductive dehalogenation reactivity within a given mechanism.

20 FurthermoreFinally, we have proposed new dual isotope analyses for distinguishing the various

21 environmental dehalogenation mechanisms. 
1 KEYWORDS: reductive dehalogenation, cobalamin, competing pathways, density functional

2 theory, standard-reduction potential, inner-sphere pathway, dual isotope analyses

\section{Introduction}

The widespread industrial application of halogenated compounds as solvents, chemical

6 intermediates and pesticides are of great environmental concern, with due to the adverse effects

7 on ecosystems and human health. ${ }^{1-2}$ The negative effects of halogenated compounds are generally

8 attributed to the halogen atoms $s^{-}$thus, the transformation of halogenated compounds to less- or

9 non-halogenated products is a promising remediation strategy. ${ }^{3-4}$ Among various dehalogenation

10 remediation strategies, cobalamin (vitamin B12) promoted dehalogenation reactions have garnered

11 considerable attention, owing to evidence that the cell component responsible for dehalogenation

12 reactions by several anaerobic bacteria is most likely this transition-metal coenzyme. ${ }^{5}$

Cobalamin is the largest by molecular mass and arguably the most complex (in terms of functional groups) cofactor in biology, consisting of a cobalt atom coordinated by four nitrogen atoms of the corrin ring, as shown in Scheme 1. Under non-reducing conditions, the cobalt atom commonly exists in the +3 oxidation state (cob(III)alamin), axially coordinating two ligands

17 (methyl or cyanide group in the "upper” and 5,6-dimethylbenzimidazole (DMB) in the "lower”).

${ }^{7}$ In abiotic systems, cob(III)alamin can be reduced to 4-coordinated cob(I)alamin without axial

19 ligands in the presence of strong reducing agent in aqueous media ${ }_{5}^{8-9}$ while this model These model systems mimicking microbial dehalogenation has have been used in abiotic remediation strategies for treatment of contaminated field sites. ${ }^{10}$ Compared with the rigorous selectivity of

Commented [KPK1]: This refers to previous sentence, i.e. the cob(I)alamin. Is this correct? Otherwise specific which type of model systems 
1 higher alkanes, ethylenes, arenes, etc. ${ }^{11-12}$ ThusAccordingly, the abiotically reductive

2 dehalogenation by cobalamin has substantial potential for use in remediation approaches ${ }_{2}^{;}{ }^{10,13-14}$

3 while some other transition metal complexes (e.g. iron porphyrin) as well as nano-scale zero-valent

4 metal systemss (e.g. iron, zinc, et al.etc.) have also been reported to be potentially gooduseful

5 reductive dehalogenation catalysts. ${ }^{15-17}$ Practically $_{2}$ degradation of halogenated compounds by

6 reductive dehalogenation reactions may occur via numerous routes. In order to assess whether the

7 dehalogenation brings about significant detoxification, the fundamental knowledge of the

8 reductive dehalogenation mechanisms involving cobalamin is essential. However, cob(I)alamin

9 contains the unusual combination of properties that it isof being both a strong reductant ${ }_{\overline{5}}^{18}$ and one of the most powerful nucleophiles that is $\sim 10^{4}$ times more nucleophilic than the $\mathrm{Cl}$ anion in $\mathrm{S}_{\mathrm{N}} 2$

11 reactions, ${ }^{19}$ which makes the reaction modes more diverse and complex.

12

Scheme 1. Structure of the Cobalamin

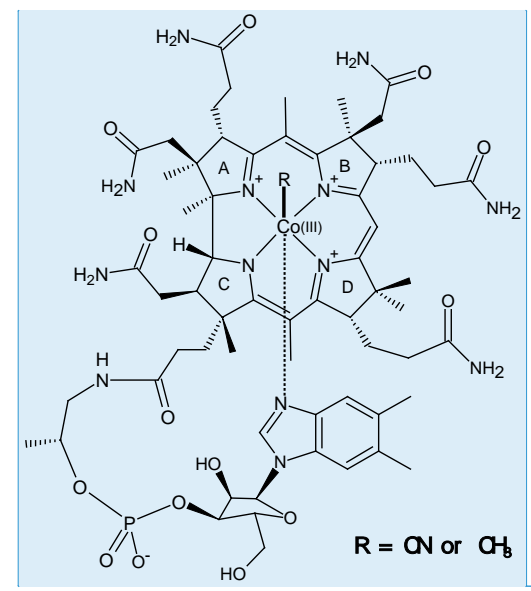

Commented [KPK2]: I don't think I mention this number specifically, perhaps another reference? 
2 reductive dehalogenation of chloroethylenes; has attracted particular attention. ${ }^{11} \mathrm{Cob}(\mathrm{I}) \mathrm{alamin}$ has

3 been reported to participate in the sequential dehalogenation of perchloroethylene (PCE), trichloroethylene (TCE), cis-1,2-dichloroethylene (cis-DCE) , trans-1,2-dichloroethylene (transDCE), and vinyl chloride (VC), resulting in the production of nontoxic ethylene. ${ }^{9,20-25}$ As shown in Scheme 2, the initial step for cob(I)alamin-catalyzed chloroethylenes can be summarized as an 7 outer-sphere (reaction occurring between chemical species with remainingin a non-connected state) or an inner-sphere (with a chemical bond forming between chemical species during the reaction)

9 process, which can be categorized in more detailmore specifically as single electron--transfer [outer-sphere (path a)], nucleophilic substitution [inner-sphere (path b)], and nucleophilic addition

11 [inner-sphere (path c)] mechanisms. Most previous work focused on the reductive dehalogenation 12 mechanism of highly_-chlorinated substances, PCE and TCE. ${ }^{9}$ 21, 23-25 On the basis of kinetic 13 experiments, the $\mathrm{pH}$-independent rate constants were observed, which may rules out inner-sphere 14 nucleophilic addition route-proceeding with simultaneous protonation. ${ }^{21-22}$ Meanwhile, 15 cob(I)alamin-mediated dehalogenation of PCE and TCE with increasing amounts of $d_{7}$ 16 isopropanol, a D• donor, resulted in as at most $10 \%$ of the PCE-derived deuterated products and $1730 \%$ of the TCE-derived deuterated products, in agreement with outer-sphere one-electron 18 transfer. ${ }^{21}$ However, this outer-sphere mechanism is not in accord with stereochemical results that 19 the dehalogenation of TCE by cob(I)alamin produces greater amount of cis-DCE compared to 20 trans-DCE (> 15:1), markedly different from the ratio obtained with identified electron-transfer 21 reagents $(<5: 1) \cdot{ }^{23}$ Supporting for the nucleophilic substitution mechanism originated from 22 experimental observation that theof molecular mass consistent with dichlorovinylcobalamin had 23 been observed in mass spectra during the TCE dehalogenation reaction. ${ }^{25}$ If this nucleophilic 
1 substitution mechanism works for PCE with cob(I)alamin as well, the trichlorovinylcobalamin

2 from the PCE dehalogenation reaction should be detected, but this has not been the case. ${ }^{11}$

3 The experimental work performed with isopropyl alcohol- $\mathrm{d}_{7}$ at different concentrations has

4 showed that, in contrast to PCE and TCE, there were not markedwere only few-deuterated products

5 captured for the cobalamin-catalyzed reductive dehalogenation of less-chlorinated substances, cis-

6 DCE, trans-DCE, and VC. It This indicates that there is not significant quantities $y$ of free radicals

7 produced in during the dehalogenation process. Meanwhile, the kinetic experiments have shown

8 that cobalamin reductively dehalogenate ${ }$ cis-DCE, trans-DCE, and VC in pH-dependent

9 reactions. $^{22}$

10

11 Scheme 2. Alternative Reaction Mechanisms for Reductive Dehalogenation of Chloroethylene

\title{
12 Catalyzed by Cobalamin ${ }^{a}$
}

13

17 has been investigated using compound specific isotope analysis (CSIA). ${ }^{9}$ 26-31 CSIA is able te

${ }^{a}$ taking PCE as an example

Isotope fractionation in-during reductive dehalogenation of chloroethylenes with cobalamin

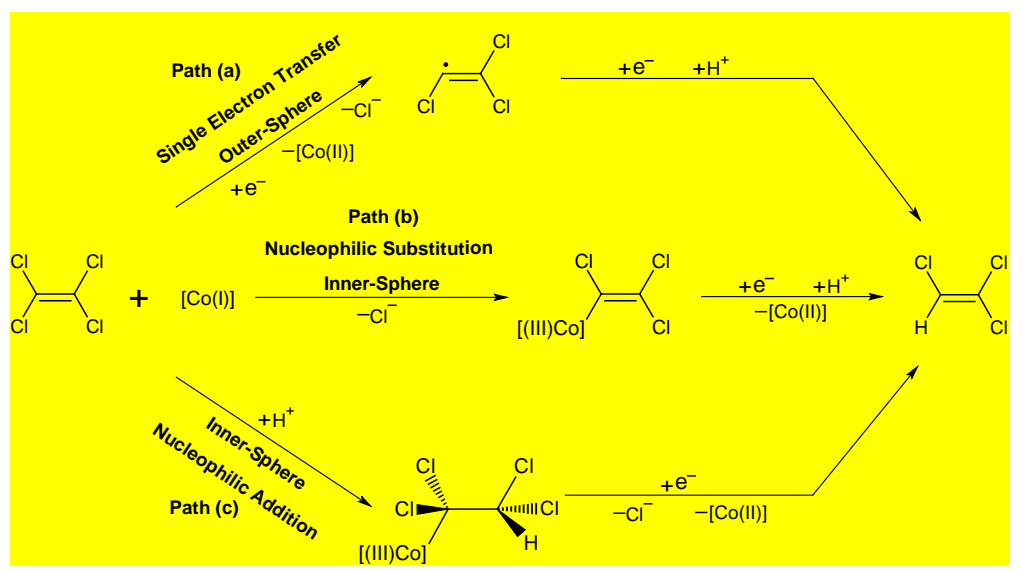
(1)

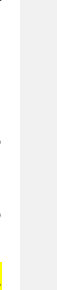


1 offers new insight into the organic pollutant degradation mechanism, especially when the

2 competing reaction pathways are unknown. ${ }^{32-33}$ In the process of cobalamin-mediated reductive

3 dehalogenation of chloroethylenes, most previous work focused on stable carbon isotopes, and

4 stable chlorine isotopes were not commonly studied-so often. For example, the reported carbon

5 bulk isotope fractionation factors ( $\varepsilon_{\text {bulkC }}$ ) are $-15.8 \%$ for $\mathrm{PCE}^{26}$ and $-16.1 \%$ for $\mathrm{TCE}^{9}$; however,

6 in contrast to cobalamin-catalyzed PCE and TCE, the reported values for cis-DCE $(-25.5 \% \text { o })^{27}$ and

$7 \quad$ VC $(-31.1 \%)^{28}$ are much larger, which may indicate an entirely different reductive dehalogenation

8 mechanism. Until now, no systematic computational investigation of isotope fractionation within

9 the different operative pathways for reductive dehalogenation of chloroethylenes in the presence

10 of cobalamin has been undertaken although such investigation should shed light onto this ongoing

11 mechanistic debate.

12 Computational analysis of the catalytic mechanism can provide insight into the electronic

13 structure features governing reaction mechanisms ${ }_{-3}{ }^{34-43}$ which has already been performed to

14 giveSuch studies have provided insight into the viability of various intermediates and pathways in

15 the reductive dehalogenation of chloroethylenes with cobalamin ${ }^{44-46}$ as well as synthetic

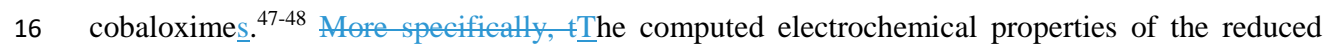

17 chloroethylenes and chlorinated-cobalamins have been useful for interpreting some experimental

18 observations, such ase.g. indicating that the formed chlorinated vinyl radicals during reductive

19 dehalogenation may be reduced to anionic forms competing with their rebound to cob(I)alamin to

20 produce vinylcobalamins. ${ }^{44}$ It is noteworthy thatNotably, most work has used the cobalamin

21 structure-simplified through eutting off thecorrin model without side chains and replacing the axial

$22 \mathrm{DMB}$ base with imidazole instead of DMBfor studying the mechanism of reductive

23 dehalogenation, yet these substituents can affectcobalamin eelctronic structure substantially, so

Commented [KPK4]: I suggest citing my paper Kepp 2014 (reference 55 in the current version) where I study full cobalamins and show that these side chains are important. 
1 while the influence of omitting the substituents and substitution ofusing the simpler axial base

2 needs to be addressed. Until now, the precise reductive dehalogenation mechanism has not been

established in details that would warrant explanation of all experimental observations collected so far.

In this work we use density functional theory (DFT) on realistic full cobalamin structures to address the following unsolved mechanistic questions: (i) why $\mathrm{pH}$-independent rate constants have only been observed for the reactions of PCE and TCE with cobalamin, but not for cobalamincatalyzed reactions of cis-DCE, trans-DCE, and VC; (ii) why there is conflicting evidence for the dehalogenation processes of cobalamin-mediated PCE and TCE favoring either the outer-sphere pathway or the inner-sphere pathway, respectively; (iii) why only dichlorovinylcobalamin has been detected during upon reaction of TCE with cobalamin, but not trichlorovinylcobalamin in the reaction of cobalamin-mediated PCE; (iv) whether the comparison between calculated kinetic isotope effects (KIEs) and experimental apparent kinetic isotope effects (AKIEs) can be used to identify the competing dehalogenation pathways.

\section{Computational Methodology}

The System for Cobalamin-Mediated Chloroethylenes Computational Details. All calculations in this work were performed with the Gaussian 09 Revision D. 01 program package. ${ }^{70}$

The complete 4-coordinated cob(I)alamin species (with the nucleotide loop is clippedoff), was-were used as initial structurebasis for our computational work. The geometry optimizations and frequency analyses have beenwere carried out in the gas phase using the Perdew-BurkeErnzerhof (PBE) functional, ${ }^{49-50}$ combined with Ahlrich's TZV basis set ${ }^{51}$ for Co and 6-31G** basis set ${ }^{52}$ for $\mathrm{C}, \mathrm{N}, \mathrm{H}, \mathrm{O}$ and $\mathrm{Cl}$ (denoted as-BSI). The PBE functional has been previously shown 
1 to accurately reproduces the experimental frequencies of the corrin-based normal modes of

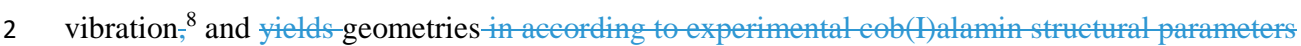

3 from XAS studies ${ }_{53}^{53-54}$ and accurate Co-C bond dissociation energies ${ }^{55}$. Subsequent frequency

4 calculations were run to confirm that all ground states had only real frequencies, whereas the transition states had one imaginary frequency. The computed vibrational frequencies were further

6 used to quantify the zero-point energy correction (ZPE); and enabled us to convert the electronic

7 energy to the Gibbs free energy at $298.15 \mathrm{~K}$ and $101.325 \mathrm{kPa}$. The iIntrinsic reaction coordinate

8 (IRC) calculations were performed further to verify that the transition states really actually

9 connected the reactants and products. Based on the PBE-optimized structures in the gas phase, the water solvation effects were calculated by COSMO continuum-solvation model (CPCM, dielectric

11 constant $=78.3)$ at the PBE/BSI level of theory. The dispersion interactions were eonsidered

12 through doingincluded via single-point calculations at the PBE-D3/BSI level of theory, due to the

13 standard DFT method lacking of such interactions. ${ }^{56}$ Unless otherwise specified, all relative free

14 energies for cobalamin-mediated chloroethylenes reactions reported were based on PBE/BSI data

15 including solvation and D3 dispersion corrections $\left(\Delta G+E_{\text {solv }}+E_{\text {disp }}\right)$. We also performed PBE-
Commented [KPK7]: If this sentence is kept XAS should be defined

Commented [KPK8]: Cite instead the 2010 reference for Grimme's D3 
2 and cob(III)alamin with singlet state and cob(II)alamin with doublet state., ${ }^{6,57}$ As further proof;

3 the calculations in this work at theSupporting this, the PBE/BSI level of theory free energy

4 including solvation and D3 dispersion corrections show for cob(I)alamin and cob(III)alamin (base-

5 off trichlorovinylcob(III)alamin) on-reveal triplet states are-at 21.3 and $18.4 \mathrm{kcal} / \mathrm{mol}$ respectively

6 higher energy, respectively, than their singlet state-species, while the cob(II)alamin on high-spin

7 quartet state is $29.1 \mathrm{kcal} / \mathrm{mol}$ higher than itsabove the low-spin doublet state-species; thus in $_{2}$ this

8 work these species were all optimized in the low-spin state.

9 Particular attention has beenwas focused on the electronic structure of cob(I)alamin. Previous computational studies have investigated the electronic structure of four 4 -coordinated cob(I)alamin

11 without the axial DMB base-and fives-coordinated cob(I)alamin with the axial DMB base using

12 DFT and CASSCF calculations. ${ }^{8,19,58}$ The-TD-DFT calculations on truncated four4-coordinated

$13 \mathrm{cob}(\mathrm{I})$ alamin have suggestedsuggest that ground state cob(I)alamin is purely a closed-shell singlet

$14 \mathrm{~d}^{8}$ species. $^{8}$ Subsequent-CASSCF calculations on the truncated cob(I)alamin have shown that the

15 dominant contribution to the ground state wave function is the closed-shell singlet $\mathrm{d}^{8} \mathrm{Co}(\mathrm{I})$

16 configuration for four- 4 -coordinated cob(I)alamin ${ }^{19,58}$ and for five $\underline{5}$-coordinated cob(I)alamin

17 with very $\underline{\text { a }}$ weakly coordinated axial base, ${ }^{58}$ while cob(I)alamin is mainly dominantly the open-

18 shell singlet/triplet $\mathrm{d}^{7} \mathrm{Co}(\mathrm{II})$-corrin $\left(\pi^{*}\right)^{1}$ diradical configuration with a strongly coordinated axial

19 base. ${ }^{58}$ Then, tThe reaction mechanisms of methyl transfer between $\operatorname{cob}(\mathrm{I})$ alamin and $\mathrm{CH}_{3}-$

$20 \mathrm{H}_{4}$ Folate $\underline{H}_{4}$ folate catalyzed by methionine synthase revealedhave been studied

21 computationally, with the four 4 -coordinated base-off cob(I)alamin conformation for studying the

$22 \mathrm{~S}_{\mathrm{N}} 2$ pathway and the five 5 -coordinated base-on cob(I)alamin conformation for studying the

23 electron-transfer pathway, giving similar barriers for these two pathways. ${ }^{36}$ However, while 
1 cob(I)alamin only existing in the enzyme can coordinate to the axial DMB base due to the H-

2 bonding between the base and nearby amino acid residues, ${ }_{2}=$ The $X$-ray absorption spectroscopyie

3 experiments ${ }^{54}$ as well asand DFT computations $\underline{s}^{8}$ have shown that cob(I)alamin in solution is not

4 axially coordinated to DMB base at all, which is proved again in this work that PBE calculations

5 show the complete five coordinated cob(I)alamin on open-shell singlet/triplet state is about 22

$6 \mathrm{kcal} / \mathrm{mol}$ higher in free energy at PBE/BSI level of theory including solvation and D3 dispersion

7 corrections than the complete four-coordinated cob(I)alamin on close-shell singlet state plus DMB

8 base in solution. Supporting the strict low-spin closed-shell configurations as found in our study.

9 Furthermore, in this work, the closed shellthe singlet stability of the eomplete four 4 -coordinated cob(I)alamin was probved by mixing the highest occupied molecular orbital (HOMO) and lowest

11 unoccupied molecular orbital (LUMO) from PBEerbitals using PBE functional, and the-by

12 CASSCF single-point calculation on the complete (not truncated) four4-coordinated cob(I)alamin.

Many studies have also shown the experimentally calibrated PBE and BP86 methods are 14 accurate for ground-state thermochemistry of cobalamins, ${ }^{59}$ partly becauseand the required active 15 spaces from CASSCF e.g. CASPT2 methods are out of range to be computationally tractable, and

partly because of the basis set requirements. To summarize what has been mentioned

17 aboveAccordingly, this work focuses on the four -4 coordinated cob(I)alamin on-with the closed- shell singlet state using PBE method to study the reductive dehalogenation mechanisms.

Electrochemical Properties of Chlorinated Cobalamin. The aqueous-phase standard reduction potentials $\left(\mathrm{E}^{0}\right)$ referenced with respect to the standard calomel electrode (SCE) ( $\mathrm{E}^{0}$ vs. SCE, unit: V) of all chlorinated vinyl- and ethyl-cobalamins as well as the cob(II)alamin/cob(I)alamin couple were converted from the aqueous-phase adiabatic electron

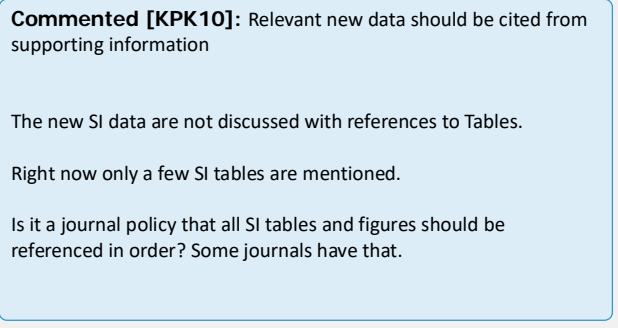

Commented [KPK10]: Relevant new data should be cited from

The new SI data are not discussed with references to Tables.

Right now only a few SI tables are mentioned.

Is it a journal policy that all SI tables and figures should be referenced in order? Some journals have that. 
1 affinities (AEA). ), while $\underline{\text { Tthe absolute reduction potential of SCE for cobalamin is applied was }}$

$24.52 \mathrm{~V}$ as recommended before, ${ }^{60}$ as shown in eq 1 :

3

$\mathrm{E}^{0}$ vs. SCE $(\mathrm{V})=\mathrm{AEA}-4.52$

4 The AEA values were in the form of free energy changes, using the PBE single-point

5 calculations obtained fromon the PBE/BSI-optimized geometries using the larger 6-311+G(2d,2p)

6 basis set ${ }^{61}$ for main group atoms and TZV for cobalt (denoted as BSII), including solvation

7 energy and B3-dispersion corrections (BSII level of theory), and free energy corrections (BSI level

8 of theory). The vertical electron affinities (VEA) for the base-off and base-on less-chlorinated

9 ethylcobalamins were obtained from PBE/BSII//BSI single-point calculations with water solvation 10 and D3 dispersion corrections. Note fFor cob(II)alamin and all chlorinated-cob(II)alamins en-with 11 doublet states, $\mathrm{S}^{* * 2}$ values after annihilation are range from 0.7500 to 0.7502 , thus $\underline{\text { i.e. }}$ there are 12 no spin contaminations of the wavefunctions for all doublet cob(II)alaminof these species.

Electrochemical Properties and Electrophilic Reactivity of Chloroethylenes. All calculations for the electrochemical properties of chloroethylenes were performed using the PBE/aug-cc-pVTZ level of theory (BSIII) with CPCM solvation model of aqueous solution (dielectric constant $=78.3$ ). VEA for all chloroethylenes are electronic energy differences in aqueous-phasewater, while adiabatic electron affinities for all vinyl radicals are aqueous-phase free energy change in waters. The adiabatic electron affinities of vinyl radicals were translated into aqueous-phase $\mathrm{E}^{0}$ vs. SCE. The eElectrophilic index $(\omega)$, developed frombased on the concept of the hard and soft acids and bases (HSAB), ${ }^{62-64}$ were-was calculated to characterize the electrophilic

21 reactivity of chloroethylenes. In order to calculate the electrophilic index $(\omega)$, firstly the highest

Formatted: Superscript

Commented [KPK11]: HOMO was already mentioned previously; explain at first incidence 
quantify the three basic HSAB parameters as follows: hardness $(\eta)$ as $\left(\mathrm{E}_{\mathrm{LUMO}}-\mathrm{E}_{\mathrm{HOMO}}\right) / 2$, softness $(\sigma)$, defined as the inverse of hardness $(1 / \eta)$, and the chemical potential $(\mu)$, as $\left(\mathrm{E}_{\mathrm{LuMO}}+\mathrm{E}_{\mathrm{HOMO}}\right) / 2$. Then, the electrophilic index $(\omega)$ was calculated as $\mu^{2} / \eta$.

Kinetic Data. The reaction rate constant of for reaction of the chloroethylenes with $\operatorname{cob}(\mathrm{I})$ alamin, $\mathrm{k}$, and the corresponding free energy of activation, $\Delta \mathrm{G}^{\neq}$, can beare converted to each ether according terelated by the Eyring equation (eq 2):

$$
\mathrm{k}=\frac{\mathrm{k}_{\mathrm{B}} \mathrm{T}}{\mathrm{h}} \cdot \frac{1}{\mathrm{c}^{0}} \exp \left(-\frac{\Delta \mathrm{G}^{\neq}}{\mathrm{RT}}\right)
$$

where $\mathrm{k}_{\mathrm{B}}$ is the Boltzmann constant, $\mathrm{h}$ is the Planck constant, $\mathrm{R}$ is the gas constant, $\mathrm{T}$ the temperature in Kelvins, and $c^{0}$ is the concentration defining the standard state (typically 1 mol/L). This

\section{equation was used to estimate relative rate constants from activation barriers.}

Isotope Effects. ${ }^{65-67}$ The ebtained-Hessians obtained from the above mentioned-frequency calculations after geometry optimizations-were used to calculate kinetic isotope effects (KIEs) with using the ISOEFF package. ${ }^{68}$ KIEs were obtained according to the Bigeleisen equation at $298 \mathrm{~K}$ for the transition from two separate reactants to the corresponding transition state. The apparent

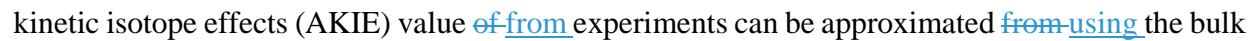
isotope fractionation factors ( $\left.\varepsilon_{\text {bulk }}\right)$ by eq 3 :

$$
\mathrm{AKIE} \approx \frac{1}{1+\mathrm{n} / \mathrm{X} \cdot \mathrm{z} \cdot \varepsilon_{\mathrm{bulk}}}
$$

where $\mathrm{n}$ is the number of atoms of the considered element, $\mathrm{x}$ is the number of atoms of the considered element at the reactive position, and $\mathrm{z}$ is number of atoms of the eonsidered-element in intramolecular isotopic competition. ${ }^{33}$ It should be noted that in this form the secondary isotope effects are neglected, an assumption that should be plausibleis reasonable for chlorine KIEs. ${ }^{69}$
Commented [KPK12]: Just a point perhaps to mention: These calculations assume 1) Koopman's theorem applies to make HOMO /L UMO resemble IP and EA, and 2) the finite difference approximations to hardness and chemical potential viz. the Mulliken electronegativity 
pare ${ }^{70}$

3

4 Results and Discussion.

\section{Calibration vs. Experimental Data-}

Based on DFT optimization results with the PBE functional,Our DFT computations show that

two-electron reduction of the complete model of cob(III)alamin to cob(I)alamin leads to both the

8 axial methyl and DMB groups leaving off, providingto produce the 4-coordinated cob(I)alamin species (, as shown in-Figure 1), as expected. The corrin macrocycle in the complete cob(I)alamin model is almost planar with averaged Co-N bond length of $1.86 \AA$. This is in consistent withfits the average Co-N bond lengths of 1.86 and $1.88 \AA$ reported in two recent XAS studies. ${ }^{53-54}$ In addition, the calculated standard reduction potential $\left(\mathrm{E}^{0}\right)$ value for the $\operatorname{cob}(\mathrm{II})$ alamin/cob(I)alamin couple is $-0.78 \mathrm{~V}$ vs. SCE, near to the corresponding experimental data of $-0.85 \mathrm{~V}$ vs. SCE, ${ }^{18}$ further validating the reliability of the theory level used.

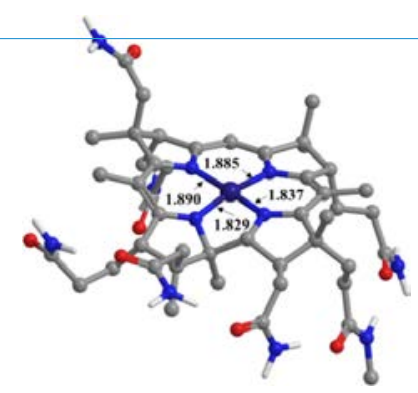

Figure 1. Chemical Structure along with Bond Lengths of Planar Co-N Bonds $(\AA)$ for Cob(I)alamin.
Formatted: Indent: First line: $0,85 \mathrm{~cm}$

Formatted: First line: $0 \mathrm{ch}$

Formatted: Font: Not Bold Figure 1.

It is not a figure with a lot of information currently and some journals emphasize merging figures with more panels when this happens 
2 glycine)] and water molecular has been revealed experimentally at very low_temperature, ${ }^{71}$ which

3 supportsindicating that the $\mathrm{d}^{8}$ metal ions in complexes can act as H-bonding acceptors. Considering

4 the fact that the dominant contribution to the ground state is the closed-shell singlet $\mathrm{d}^{8} \mathrm{Co}(\mathrm{I})$ for

$5 \operatorname{cob}(\mathrm{I})$ alamin, a scientific questionthe possibility arises that whethethat the $\mathrm{Co}(\mathrm{I}) \cdots \mathrm{H}$ interaction

6 between $\operatorname{cob}(\mathrm{I})$ alamin and a water molecule molecular can also be formed and consequently

7 influence the $\operatorname{cob}(\mathrm{II}) \mathrm{alamin} / \mathrm{cob}(\mathrm{I}) \mathrm{alamin}$ reduction. Then rRelevant computational

8 computationscalculations have been done, ${ }^{72}$ which confirms the possibility of forming the $\underline{a}$

$9 \mathrm{Co}(\mathrm{I}) \cdots \mathrm{H}$ linkage between cob(I)alamin and water molecular from thermodynamics, and suggests

10 that this unusual $\mathrm{Co}(\mathrm{I}) \cdots \mathrm{H}$ interaction may have significant catalytic relevance during the

11 reactivation cycle of the methionine synthase enzyme. ${ }^{73-74}$ Therefore, the $\mathrm{Co}(\mathrm{I}) \cdots \mathrm{H}$ as well as

$12 \mathrm{Co}(\mathrm{I}) \cdots \mathrm{Cl}$ interactions between $\operatorname{cob}(\mathrm{I})$ alamin and chloroethylenes have beenwere explored in this

13 work. As shown in Table 1, all $\mathrm{Co}(\mathrm{I}){ }^{\cdots} \mathrm{H}$ and $\mathrm{Co}(\mathrm{I}){ }^{\cdots} \mathrm{Cl}$ bond formation processes between cob(I)alamin and different chloroethylenes are endothermic in water solution based on the PBE/BSI free energies including solvation and D3 dispersion corrections, which seem to be 16 nonspontaneous from thermodynamics. This is in accord with previous computations suggesting 17 the earlier computational study that the $\operatorname{Co}(\mathrm{I}) \cdots \mathrm{H}$ bond formation between $\operatorname{cob}(\mathrm{I})$ alamin and $\underline{\mathrm{a}}$ 18 water molecular molecule in water solution wasis not favorable in water solution where water19 water inetractions are favored, ${ }^{72}$ and- in line with previous experiments indicating al work that 20 there was no such observed-H-bonding in water solution. ${ }^{18}$ Therefore, this work usesWe thus used 21 the two separate reactants (i.e., cob(I)alamin and chloroethylene) as starting point to study the 22 reductive dehalogenation mechanisms in the following sections. However, since the earlier 
mimicking ofwith a dielectric constant similar to that of a typical protein environment) made

2 makes the $\mathrm{Co}(\mathrm{I}) \cdots \mathrm{H}$ bond formation process favorablefeasible, this unusual $\mathrm{Co}(\mathrm{I}) \cdots \mathrm{H}$ or even

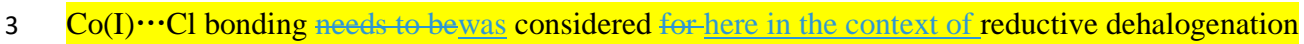

4 catalyzed by cob(I)alamin in enzyme.

5

6 Table 1. Computed Free Energies $(\mathrm{kcal} / \mathrm{mol})$ at the PBE/BSI level of theory with solvation and

D3 dispersion corrections for $\mathrm{Co}(\mathrm{I}) \cdots \mathrm{H}$ and $\mathrm{Co}(\mathrm{I}){ }^{\cdots} \mathrm{Cl}$ Bond Formation between $\mathrm{Cob}(\mathrm{I})$ alamin and Chloroethylenes in Water Solution

9

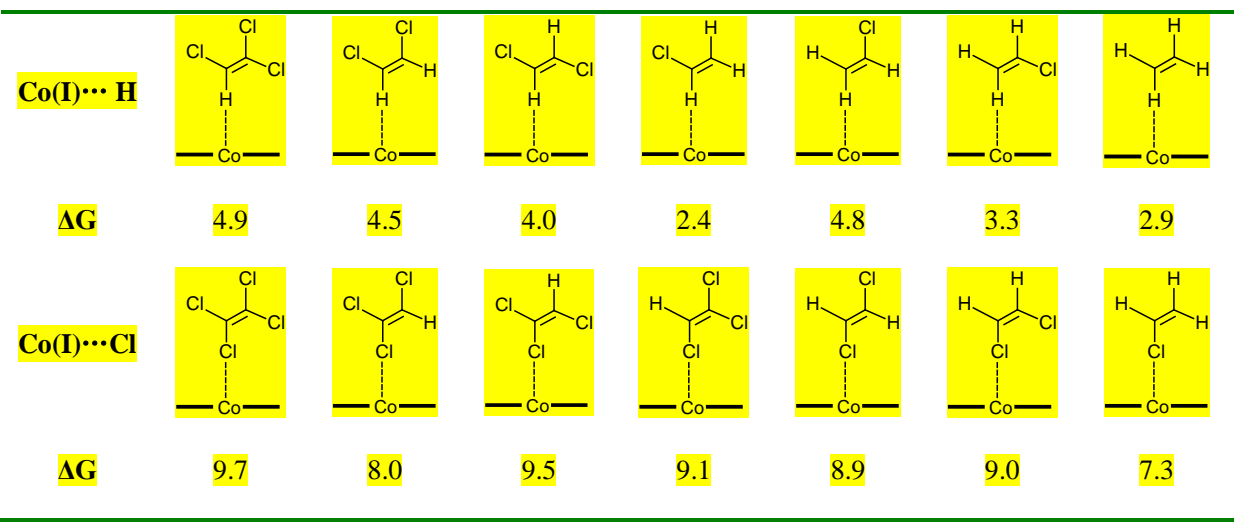

10

11

\section{Outer-Sphere Electron Transfer Mechanism.}

We firstly focus on the outer-sphere electron transfer pathway of cob(I)alamin catalyzing
Commented [KPK16]: Mention where these data are discussed, sounds more like method right now

Formatted: Indent: First line: $0,85 \mathrm{~cm}$

Formatted: First line: $0 \mathrm{ch}$ 
1

2 DMB: 5,6-dimethylbenzimidazole

3 The free energy barriers of the outer-sphere electron transfer processes $\left(\Delta \mathrm{G}^{\neq}\right.$ET $)$can be estimated

4 from the Marcus theory ${ }^{75-78}$ (calculation details shown in the Supporting Information). The

5 obtained $\Delta \mathrm{G}^{\neq} \mathrm{ET}$, the free energy of reaction $\left(\Delta \mathrm{G}_{\mathrm{ET}}\right)$ as well asand the vertical electron affinities

6 (VEA) values for all chloroethylenes are shown in Table 2. Both $\Delta \mathrm{G}^{\neq} \mathrm{ET}$ and $\Delta \mathrm{G}_{\mathrm{ET}}$ values increase

7 in the sequence PCE $<$ TCE $<$ trans-DCE $<$ cis-DCE $<$ VC, with increasing number of chlorine

8 atoms and decreasing of the vertical electron affinities (VEA) values. Then a linear free energy

9 relationship (LFER) between $\Delta \mathrm{G}^{\neq} \mathrm{ET}$ and VEA values for the one-electron-transfer reaction was

10 builtconstructed. As a result, tThe VEA values are closely correlated to with the free energy

11 barriers with an $r^{2}$ of $0.940\left(\Delta \mathrm{G}_{\mathrm{ET}}^{\neq}=-67.02 \mathrm{VEA}+104.11\right)(\mathrm{in} \mathrm{kcal} / \mathrm{mol})$. Therefore, it is possible

12 to provide a computationally less demanding tool for preliminary evaluation of the free energy

13 barriers of the electron transfer process for cobalamin-mediated reductive dehalogenation of halogenated compounds within one class.

15

Affinities (VEA, eV) of Chloroethylenes

\begin{tabular}{c|ccccc}
\hline & PCE & TCE & cis-DCE & trans-DCE & $\mathbf{V C}^{a}$ \\
\hline $\mathbf{V E A}$ & 1.36 & 1.24 & 1.02 & 1.13 & 0.97 \\
$\Delta \mathbf{G}^{\neq}{ }_{\mathbf{E T}}$ & 15.9 & 17.6 & 34.7 & 27.3 & 41.7 \\
$\boldsymbol{\Delta} \mathbf{G}_{\mathrm{ET}}$ & 15.6 & 17.2 & 31.0 & 25.7 & 35.2 \\
\hline${ }^{a}$ VC: vinyl chloride & & & &
\end{tabular}

Note that the outer-sphere electron transfer reactions for all chloroethylenes by cob(I)alamin

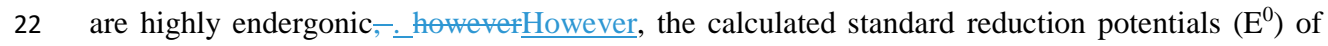


1 vinyl radicals listed in_(-Table S3 in the Supporting Information) show that all chlorinated vinyl

2 radicals thave $\mathrm{E}^{0}$ values between $-0.40 \mathrm{~V}$ to $0.16 \mathrm{~V}$, i.e. they can be reduced at standard

3 conditions by cob(I)alamin, which could provide additional driving force for the reaction to

4 proceed. The free energy barrier-values for PCE and TCE are considerably lower $(<20 \mathrm{kcal} / \mathrm{mol})$,

5 implicating

6 PCE and TCE could take place at normal temperatures, but such reactions are hampered by the high barrier for cob(I)alamin catalyzing trans-DCE, cis-DCE and VC. These results are consistent

8 with experimental findings- that no significant amount of free vinyl radicals were produced in the

9 reactions of cob(I)alamin reducing trans-DCE, cis-DCE and VC, while significant chlorinated vinyl radicals formed during the reactions of PCE and TCE catalyzed by cob(I)alamin. ${ }^{22}$ In the following sections, the competition between the outer-sphere and inner-sphere reduction of chloroethylenes with cob(I)alamin will be addressed.

13

\section{Inner-Sphere Nucleophilic Substitution Mechanism.}

Figure 2 shows the free energy profile for the inner-sphere nucleophilic substitution of PCEwith cob(I)alamin, together with geometric details of the relevant molecular species. From separated reactants, cob(I)alamin + PCE, the nucleophilic substitution reaction takes place via the concerted transition state $\mathrm{TS}_{\mathrm{NS}}$, associated with a barrier of $14.2 \mathrm{kcal} / \mathrm{mol}$, leading synchronously to base-off trichlorovinylcob(III)alamin tnder upon loss of ehloride anion-Cl!- (the Mulliken charge of dissociatedof $\mathrm{Cl}$ changes from 0.11 in the reactants to -0.65 in the products), slightly exothermic of $-0.2 \mathrm{kcal} / \mathrm{mol}$ relative to reactants. The experimental second-order rate constant of cob(I)alamin-mediated PCE varied slightly with $\mathrm{pH}\left(\right.$ 7_— $\left._{\sim}\right)$, from $125 \pm 7$ to $179 \pm 10 \mathrm{M}^{-1} \mathrm{~s}^{-1}$. $^{21}$ Thus bringing the kinetic information inteUsing the Eyring equation (eq 2); yields a free energy
Commented [KPK17]: Ability to reduce also depends on $\mathrm{P}$ and $R$ concentrations viz. Nernst equation, but at 1:1 encounters during the reaction this would be thermodynamically favorable

Formatted: Indent: First line: $0,85 \mathrm{~cm}$

Formatted: Indent: First line: $0 \mathrm{ch}$

Commented [KPK18]: It is was completely lost it would be nonbonded and -1 charge since we are talking about the product?

Formatted: Superscript

Commented [KPK19]: One could imagine very electronegative atoms with very negative Mulliken charge that are still nit

dissociated but simply attracts electron density. Bond distance is probably more relavnt as a measure of dissociation

Commented [KPK20]: The means approximate, not interval 
1 barrier from of 14.3-to-14.6 kcal/mol, very close to the above calculated nucleophilic substitution

2 barrier of PCE with cob(I)alamin. The qualitative comparison of the free energy barriers of

3 nucleophilic substitution $\left(\Delta \mathrm{G}^{\neq} \mathrm{NS}=14.2 \mathrm{kcal} / \mathrm{mol}\right)$ and electron transfer $\left(\Delta \mathrm{G}_{\mathrm{ET}}^{\neq}=15.9 \mathrm{kcal} / \mathrm{mol}\right)$

4 estimates thesuggests a pathway ratio of nucleophilic substitution to electron transfer of $\sim 17: 1$, in

5 accord with the experimental phenomenon that maximally ten percent $10 \%$ free radicals are formed

6 during dehalogenation of PCE with cob(I)alamin, resulted in thei.e. a ratio for inner-sphere

7 pathway to out-sphere pathway of more tham $\geq 10: 1 .^{21}$ No minima along the reaction path

8 corresponding to initial cob(I)alamin - PCE adduct could be located, and the IRC calculations

verified the reaction path leading down from the transition state to separate cob(I)alamin and PCE as reactants (reverse direction) and base-off trichlorovinylcob(III)alamin as product (forward direction), as shown in Figure $\mathbf{S 3}$ in the Supporting Information. The $\mathrm{A}$ characteristic $\mathrm{S}_{\mathrm{N}} 2$

12 transition-state geometry, with bond making occurring simultaneously with bond breaking, is 13 easily recognized. This $\mathrm{S}_{\mathrm{N}} 2$ transition-state geometry is rather unsymmetrical with the forming $\mathrm{C}$ Co bond (2.05 $\AA$ ) much shorter than the breaking $\mathrm{C}-\mathrm{Cl}$ bond $(2.40 \AA)$.

15

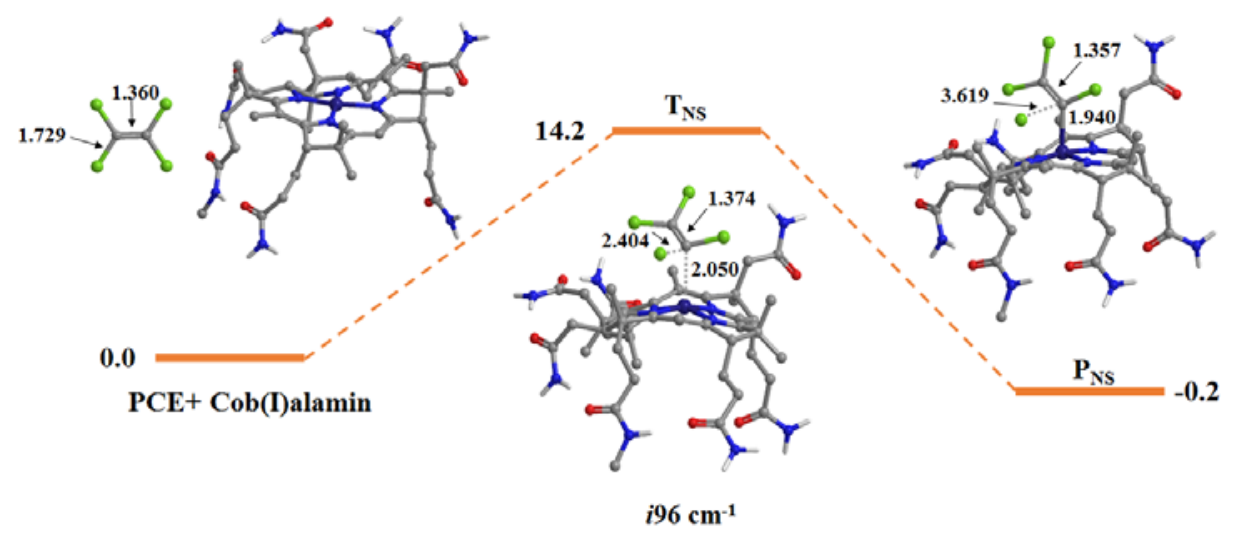


1 Figure 2. Free Energy Profile (kcal/mol) of $\operatorname{Cob}(\mathrm{I})$ alamin-mediated Reductive Dehalogenation of

3 in Transition State in wave numbers. Relative Energies-energies were given in the Form of based

PCE, along with the Optimized Geometries $(\AA)$ of the Key Species and the Imaginary Frequency on PBE/BSI Free free Energies-energies with Singlesingle-Point-point Solvation-solvation and D3

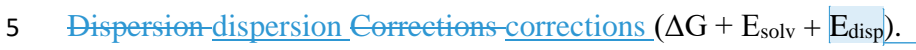

Electrochemical experiments ${ }^{79}$ and DFT calculations ${ }^{80}$ have demonstrated that the oneelectron-reduced alkyl-cobalt complexes exhibit significant lowering of the Co-C bond dissociation energy in comparison to their neutral precursors. Therefore, once the trichlorovinylcobalamin is formed, it is essential to investigate the subsequent reductive cleavage processes of Co-C bond for both the base-off and base-on trichlorovinylcobalamins, to give the dehalogenation product of PCE, i.e. TCE. The calculated $\mathrm{E}^{0}$ for base-off and base-on trichlorovinylcobalamins are $-0.63 \mathrm{~V}$ vs. SCE and $-0.58 \mathrm{~V}$ vs. $\mathrm{SCE}_{2}$ respectively. In combination with the calculated $\mathrm{E}^{0}$ of $-0.78 \mathrm{~V}$ vs. SCE and experimental $\mathrm{E}^{0}$ of $-0.85 \mathrm{~V}$ vs. $\mathrm{SCE}^{18}$ for the cob(II)alamin/cob(I)alamin couple, it demonstrates that both the base-off and base-on

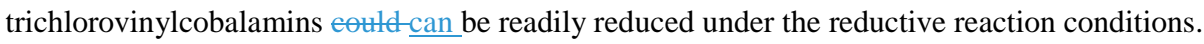

Figure 3 shows the optimized structures for both the one-electron-reduced base-off and baseon trichlorovinylcobalamin (trichlorovinylcob(II)alamin). It is remarkable that the DMB base dissociates far away from the cobalt center with Co-N length of $5.0 \AA$ for the base-on trichlorovinylcob(II)alamin, suggesting the base-on trichlorovinylcob(II)alamin probably has both the "base-on" and "base-off" properties. The complete base-on trichlorovinylcob(II)alamin with the loose axial DMB base is quite different from the previously reported simplified base-on trichlorovinylcob(II)alamin with the tight axial imidazole base, ${ }^{44}$ partly because DMB is a weaker donor ligand than imidazole and partly due to steric repulsion. Subsequently, cleavage of the Co-
Commented [KPK21]: I am not sure figure captions should be capitalized (as Tables) 
1 C bond of trichlorovinylcob(II)alamin may occur homolytically to form a vinyl anion and

2 cob(II)alamin, or heterolytically to form a vinyl radical and cob(I)alamin, as shown in Scheme 3.

3 The calculated free energies for homolysis and heterolysis of the base-off form are 29.6 and 11.0

$4 \mathrm{kcal} / \mathrm{mol}_{2}$ respectively (18.1 and $13.9 \mathrm{kcal} / \mathrm{mol}$ without dispersion correction), while the

5 corresponding values for the base-on form are 21.8 and $3.2 \mathrm{kcal} / \mathrm{mol}(-3.5$ and $-7.7 \mathrm{kcal} / \mathrm{mol}$

6 without dispersion correction). Thus, the heterolytic cleavage of the Co-C bond of the base-on

7 trichlorovinylcob(II)alamin is the most favorable pathway, which is similar to the previous

8 theoretical examination of the Co-C cleavage of reduced cis-dichlorovinylcobaloxime. ${ }^{48}$

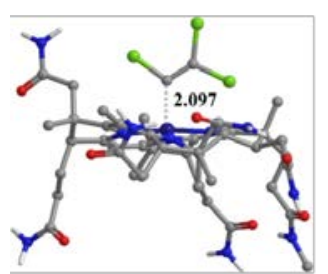

(a)

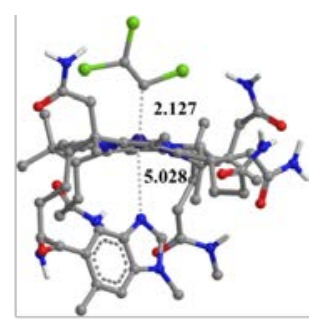

(b)
9

10

11

12

13

14

15

Figure 3. The Optimized Structures of Base-off Trichlorovinylcob(II)alamin (a) and Base-on Trichlorovinylcob(II)alamin (b).

Scheme 3. Homolysis and Heterolysis of the Base-on and Base-off Forms of Trichlorovinylcob(II)alamin
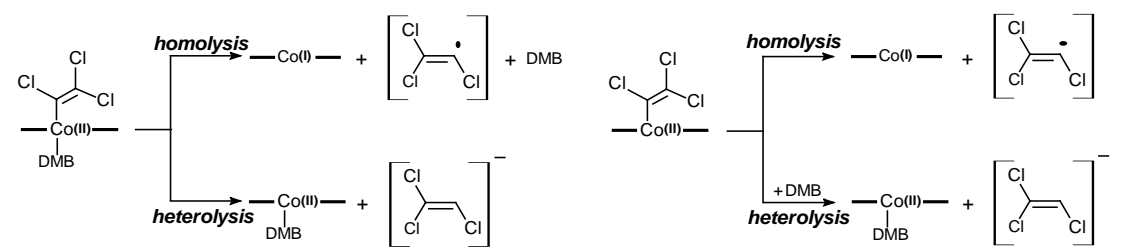

and VC. Table 3 summarizes the relative energies of inner-sphere nucleophilic substitution 3 processes for cobalamin-mediated all chloroethylenes as well as the electrophilic index $(\omega)$ for all 4 chloroethylenes., while - the optimized geometries of the $\mathrm{S}_{\mathrm{N}} 2$ transition-states are shown in

5 Figure S1 in the Supporting Information.- All the reaction paths were verified by IRC calculations

6 that the transition state leading to separate cob(I)alamin and chloroethylene as reactants in the

7 reverse direction and base-off vinylcob(III)alamin as product in the forward direction, as shown

8 in (Figure $\mathbf{S 4} \sim \mathbf{S 8}$ in the Supporting Information).. And the same as theSimilarly, for the

9 nucleophilic substitution mechanism of TCE with cob(I)alamin, no initial cob(I)alamin •

10 chloroethylene adduct could be located in the reaction path. It is obvious thatAs seen, the free

11 energy barriers of nucleophilic substitution are generally increasing with decreasing $\theta$ f-number of

12 chlorine atoms in chloroethylenes, with an exception of dehalogenation of TCE to trans-DCE with

13 larger barriers (minor pathway for dehalogenation of TCE). Moreover, quantitatively, increasing

14 the electrophilic reactivity of chloroethylenes as quantified through the electrophilic index $(\omega)$

15 decreases the nucleophilic substitution barrier, thus yielding a good correlation with an $r^{2}$ value of

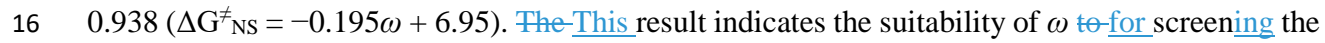

17 reactivity of cobalamin-mediated reductive dehalogenation of halogenated compounds in-via the

18 inner-sphere nucleophilic substitution pathway.

19

20 Table 3. The Relative Free Energies (kcal/mol) for Cobalamin-mediated Reductive

21 Dehalogenation of Chloroethylenes during the Inner-Sphere Nucleophilic Substitution Processes 22 along with the Electrophilic Index $(\omega)$ of Chloroethylenes

\begin{tabular}{l|llllll}
\hline & PCE & TCE $^{a}$ & TCE $^{b}$ & cis-DCE & trans-DCE & VC \\
\hline
\end{tabular}




\begin{tabular}{c|cccccc}
\hline $\boldsymbol{\omega}$ & 4.12 & 3.83 & 3.83 & 3.34 & 3.59 & 3.12 \\
$\mathbf{T S}_{\mathrm{NS}}$ & 14.2 & 16.9 & 18.6 & 18.2 & 17.3 & 19.5 \\
$\mathbf{P}_{\mathrm{NS}}$ & -0.2 & -7.9 & -1.8 & -5.1 & -6.0 & -12.5 \\
\hline
\end{tabular}

${ }^{a}$ dehalogenation of TCE to produce cis-DCE; $^{\boldsymbol{b}}$ dehalogenation of TCE to produce trans-DCE

It is apparent that $€$ Conversion of TCE may produce cis-DCE and trans-DCE, respectively.

From the relative energies in Table 3, cis-DCE is the main product under both kinetic and thermodynamic control. The computational kinetic data from the Eyring equation (eq 2) predicts a preponderance of produced cis-DCE over trans-DCE by a factor of 18 to 1 , which is in excellent agreement with the products distribution of cobalamin-mediated dehalogenation of TCE found experimentally (cis-DCE : trans-DCE ratios $>15: 1$ ). ${ }^{20-21,23}$ The energy barrier for conversion of TCE into cis-DCE gives the a rate constant of $2.5 \mathrm{M}^{-1} \mathrm{~s}^{-1}$, almost the same as the experimental data from $2.4 \pm 0.2 \mathrm{M}^{-1} \mathrm{~s}^{-1}$ to $3 \pm 0.1 \mathrm{M}^{-1} \mathrm{~s}^{-1} \cdot{ }^{21}$ Then, combining with Using the above obtained free energy barrier of the electron-transfer process $\left(\Delta \mathrm{G}^{\neq} \mathrm{ET}=17.6 \mathrm{kcal} / \mathrm{mol}\right)$ for TCE with cob(I)alamin, the ratio of nucleophilic substitution pathway to electron transfer pathway is predicted to be 3.5 : 1 through based on the Eyring equation (eq 2), consistent with the experimentally determined ratio for inner-sphere pathway to out-sphere pathway of $>2.3: 1 .^{21}$

Moreover, the reaction barriers of cob(I)alamin-mediated dehalogenation of cis-DCE, transDCE and VC are within $20 \mathrm{kcal} / \mathrm{mol}_{.,}$, thus-Accordingly, the nucleophilic substitution reactions for these less-chlorinated ethylenes by cobalamin could happen in theoryin principle occur. However, the previous experimental work has decrease of the reaction rate by roughly a factor of ten, suggesting that a proton involved in the rate-determining step, ${ }^{22}$ which contradicts the inner-sphere nucleophilic substitution pathway, to be discussed below. 
The results in former sectionabove suggest that the trichlorovinylcobalamine could be rapidly

2 reduced under reductive conditions. Therefore, it is necessary towe investigated the redox

3 potentials of other less-chlorinated vinylcobalamins to know whether they can be reduced under

4 similar conditions. Due to the preponderance production of more cis-DCE over than trans-DCE

5 for when TCE reacts with cobalamin, the following ong onlywe focused on cis-

6 dichlorovinylcobalamin-(dichlorovinyleobalamin). As shown in Table 4, the calculated $\mathrm{E}^{0}$ values

7 are becoming become more negative with decreasing offewer chlorine atoms in the chlorinated

8 vinylcobalamins, and the $\mathrm{E}^{0}$ values for all base-on dichlorovinylcobalamin, cis- and trans-

9 chlorovinylcobalamin, and vinylcobalamin are more negative than their base-off forms.

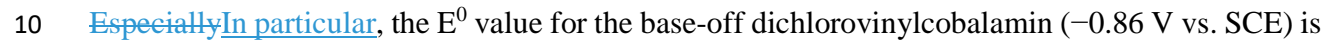

11 substantially higher than for the corresponding base-on form $\left(-1.23 \mathrm{~V}\right.$ vs. SCE), while the $\mathrm{E}^{0}$

12 values for the base-off chlorovinylcobalamins and vinylcobalamins are only a bit more positive

13 than for their base-on forms. It is obvious that aAmong these less-chlorinated vinylcobalamins,

14 only the base-off dichlorovinylcobalamin autl appear asis thus a candidate for promotion of

15 reduction by cob(I)alamin, although the $\mathrm{E}^{0}$ value-for the base-off dichlorovinylcobalamin $(-0.86$

$16 \mathrm{~V}$ vs. SCE) is a bit more negative than the $\mathrm{E}^{0}$ value offor the cob(II)alamin/cob(I)alamin couple

17 (experimental value: $-0.85 \mathrm{~V}$ vs. SCE; calculated value: $-0.78 \mathrm{~V}$ vs. SCE). All other base-off and base-on chlorinated vinylcobalamins are not feasible intermediates due to their much more negative $\mathrm{E}^{0}$ value than the cob(II)alamin/cob(I)alamin couple.

20

Table 4. Computed Aqueous-Phase Standard Reduction Potentials ( $\left.E^{0}\right)$ (V vs. SCE) for the Base-

off and Base-on Vinylcobalamins

\begin{tabular}{l|ccccc}
\hline & $\begin{array}{c}\text { trichlorovinyl } \\
\text { cobalamin }\end{array}$ & $\begin{array}{c}\text { dichlorovinyl } \\
\text { cobalamin }\end{array}$ & $\begin{array}{c}\text { cis-chlorovinyl } \\
\text { cobalamin }\end{array}$ & $\begin{array}{c}\text { trans- } \\
\text { chlorovinyl } \\
\text { cobalamin }\end{array}$ & $\begin{array}{c}\text { vinyl } \\
\text { cobalamin }\end{array}$ \\
\hline
\end{tabular}




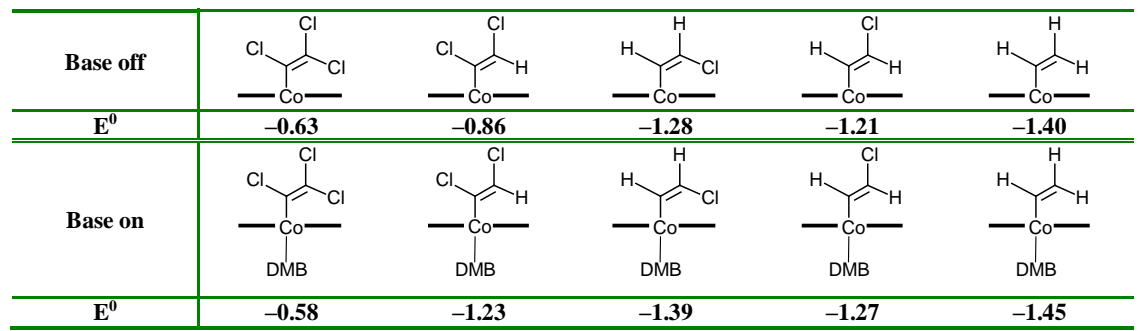

2

5 base to the Co center may be formed. As shown in Figure 4, different from the base-onin contrast

6 to trichlorovinylcob(II)alamin, the DMB base coordinates strongly with the cobalt center for the

7 to produce base-on cis-dichlorovinylcob(II)alamin. The geometry difference between the base-on

8 trichlorovinylcob(II)alamin and dichlorovinylcob(II)alamin may come arise from the much

9 stronger inductive effect of the trichlorovinyl-fragment (Mulliken charge: -0.71 ) compared to the

dichlorovinyl-fragment (Mulliken charge: -0.44) (more detailed electronic structure analysis is

11 given in the following partbelow). We then calculated the free energy changes of the Co-C bond

12 cleavage for both the base-off and base-on dichlorovinylcob(II)alamin. As for trichlorovinylcob(II)alamin, heterolysis in the base-on forms is the thermodynamically preferred 


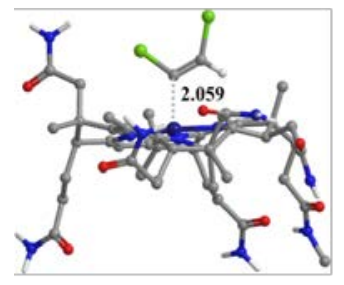

(a)

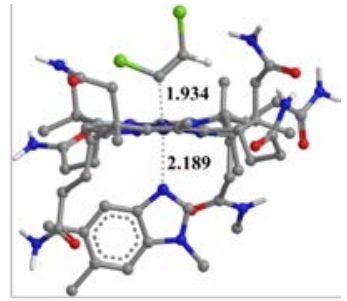

(b)

Figure 4. The Optimized Structures of Base-off Dichlorovinylcob(II)alamin (a) and Base-on Dichlorovinylcob(II)alamin (b).

It is noteworthy that detection of trichlorovinylcobalamin has never been successful, but efforts to detect dichlorovinylcobalamin have been feasible. ${ }^{25}$ This has been a long-term unsolved mechanistic topic in cobalamin chemistry. ${ }^{11}$ As mentioned above, the base-on trichlorovinylcob(II)alamin with quite long Co-N length shown in Figure $\mathbf{3}$ is close to its base-off form, making the reduction potential of the base-on trichlorovinylcobalamin ( $-0.58 \mathrm{~V}$ vs. SCE) as negative as the base-off form ( $-0.63 \mathrm{~V}$ vs. SCE), se-i.e. the base-on trichlorovinylcobalamin is easily reduced under reductive conditions. By contrast, the tight Co- $\mathrm{N}$ bond with bond length off $2.2 \AA$ ) in the base-on dichlorovinylcob(II)alamin shown in Figure 4 causes the reduction potential of the base-on dichlorovinylcobalamin $(-1.23 \mathrm{~V}$ vs. SCE) to be much more negative than its baseoff form ( $-0.86 \mathrm{~V}$ vs. SCE), resulting inimplying a relatively longer lifetime for the base-on dichlorovinylcobalamin. Thus, it is possible to observe the mass consistent with the dichlorovinylcobalamin in mass spectra of the TCE dehalogenation reaction. On the other hand, although the DMB base dissociates far away from the cobalt center for the base-on trichlorovinylcob(II)alamin, the strong destabilization effect-by the nitrogen lone pair electrons from the axialof DMB ligand-results in a weaker Co-C bond for the base-on trichlorovinylcob(II)alamin than its base-off form, and its Co-C bond would be more easily 
1 cleaved. This proposed DMB-dependence mechanism is suggested tomay be tested by distinct

2 model systems in future experimental work.

Thus, the study suggests that in an inner-sphere nucleophilic substitution pathway of PCE

4 and TCE with cobalamin, an "on/off" conformational switch change like similar to "ping-pong"

5 playing is active (see Scheme 4). Specifically, the "base-off" cob(I)alamin facilitates substrate

6 reduction, after which the formed "base-off” chlorinated vinylcobalamins can be readily reduced of PCE and $\mathrm{TCE}^{a}$

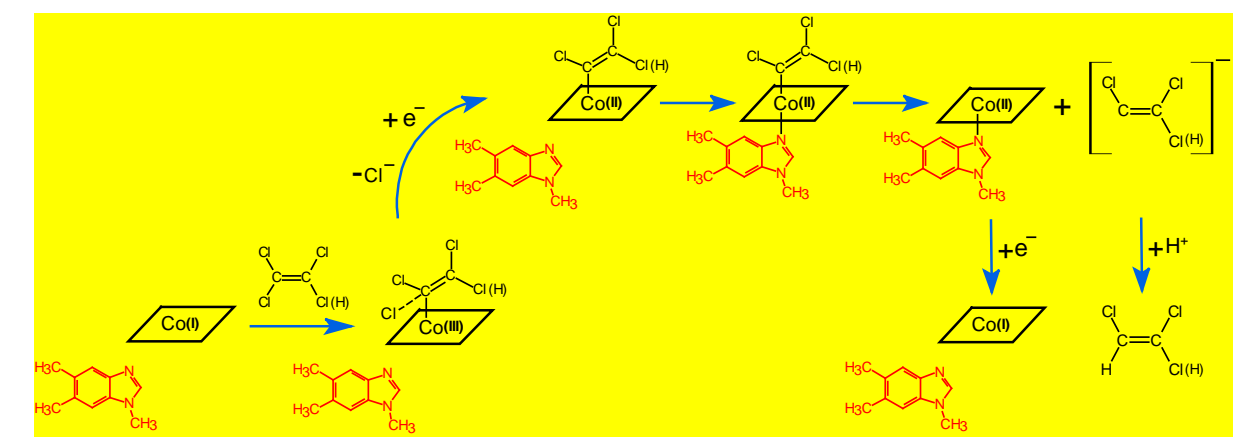

Scheme 4. The Proposed Reaction Pathway for Cobalamin-Mediated Reductive Dehalogenation 
22

24
${ }^{a}$ For cob(II)alamin and base-off tri- and di-chlorovinylcob(II)alamin, the spin is mainly localized on Co (spin density from 0.7_to 0.9), so the reactions for cob(II)alamin to cob(I)alamin with spin density from nearly one to zero and tri- and di-chlorovinylcob(III)alamin to tri- and di-chlorovinylcob(II)alamin with the spin density from zero to nearly one, really undergochanges of $\sim 1$ imply metal-centered reductions; Mulliken charges of dissociated $\mathrm{Cl}$ changes from $0.07 \_\sim 0.11$ in the reactants, $-\underline{\text { toto }}(--0.46) \sim$ to $(--0.35)$ in the transition state, and to $(--0.67) \simeq \simeq(--0.65)$ in the product complex; Mulliken charge of $\underline{T}$ The $\mathrm{CCl}_{2} \mathrm{Cl}(\mathrm{H})$ fragment changes from -0.38 $\sim-0.35$ in the base-off tri-/di-chlorovinylcob(III)alamin, to $-0.70 \sim-0.66$ in the base-off tri-/diehlorovinyleob(II)alamin, and to $0.71 \sim 0.44$ in the base-on tri/di-chlorovinyleob(II)alaminaccordingly (see Supporting Information for more (details).

\section{Inner-Sphere Nucleophilic Addition Mechanism.}

The above provides thediscussion derived the reasonable mechanistic reductivedehalogenation pathway of cobalamin-mediated PCE and $\mathrm{TCE}_{\bar{s} \overline{5}} \underline{H}_{h}$ owever, the reductive dehalogenation mechanism for cobalamin-mediated less-chlorinated ethylenes, cis-DCE, transDCE and VC, is still puzzling. Experimental work have-has shown that cis-DCE, trans-DCE and VC were reductively dehalogenated by cob(I)alamin in a pH-dependent modeway, ${ }^{22}$ suggesting that the initial and rate-determining step is possibly the addition of cob(I)alamin to these lesschlorinated ethylenes with simultaneous protonation. Therefore, the nucleophilic addition pathway is computed for cis-DCE, trans-DCE and VC according to eq 5 (taking VC as an example):

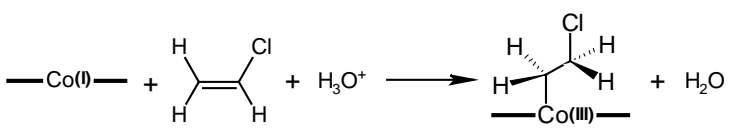

The reaction free energies $\left(\Delta \mathrm{G}_{\mathrm{NA}}\right)$ for cob(I)alamin-mediated cis-DCE, trans-DCE and VC during the nucleophilic addition pathway are $-51.9 \mathrm{kcal} / \mathrm{mol},-52.8 \mathrm{kcal} / \mathrm{mol}$ and $-48.9 \mathrm{kcal} / \mathrm{mol}$,
Formatted: Font: (Default) Times, Not Italic

Commented [KPK26]: These numbers in SI

Commented [KPK27]: Too much scheme footnote I think. Please think of shortening. I suggested some shortening.

Formatted: Indent: First line: $0,85 \mathrm{~cm}$

Formatted: First line: $0 \mathrm{ch}$ 
1 respectively. Thus, the notable driving force of the nucleophilic addition pathway for all of the

2 less-chlorinated ethylenes with cob(I)alamin to produce corresponding chlorinated

3 ethylcobalamins is evident.

Subsequently, the $\mathrm{E}^{0}$ and VEA of both the base-on and base-off chlorinated ethylcobalamins

5 were calculated ( as is shown in-Table $5_{2}$. Note that the attempts to optimize the one-electron-

6 reduced base-off dichloroethylcobalamin (dichloroethylcob(II)alamin) and chloroethylcobalamin

(chloroethylcob(II)alamin) lead directly to the elimination of chloride and formation of VC and

8 ethylene, respectively, so it is not applicable to-caleulate thecalculation of $\mathrm{E}^{0}$ is not reliablevalue

9 for the base-off less-chlorinated ethylcobalamins. At the same time, the $\mathrm{E}^{0}$ values for the baseon dichloroethylcobalamin and chloroethylcobalamin are -1.19 V vs. SCE and -1.24 V vs. SCE,

11 respectively, much more negative than the $\mathrm{E}^{0}$ value-for the cob(II)alamin/cob(I)alamin couple, i.e.

12 they are difficulthard to be-reduced. However, the VEA values of the base-off forms are larger

13 than the corresponding base-on forms, so it may be inferred that the formed "base-off dichloro-

14 and chloro-ethylcob(II)alamin” would rapidly decompose into the dehalogenation-dehalogenated

15 products. Thus, barring unexpectedly high barriers, the nucleophilic addition with simultaneous

protonation for cob(I)alamin-mediated less-chlorinated ethylenes would be favored even in basic

17 solutions with very low concentration of $\mathrm{H}_{3} \mathrm{O}^{+}$.

18 Experimental workinetic studies has have shown that VC reacted faster with cob(I)alamin

19 than cis-DCE and trans-DCE. The significance of this phenomenon is difficult to evaluate, because

20 it is challenging and error-prone to calculate the-acidity constants for transition-metal complexes

21 in solution, thereby, toand thereby obtain the free energy barriers in the nucleophilic addition

22 pathway with simultaneous protonation -is a difficult task. Nevertheless, the calculated proton

23 affinity (PA) for cis-DCE, trans-DCE and $\mathrm{VC}$ is $5.4 \mathrm{eV}, 5.5 \mathrm{eV}$ and $5.8 \mathrm{eV}$, respectively, consistent
Formatted: Font: Not Bold

Commented [KPK28]: Sometimes better to describe the type of experiments because most readers are experimentalists from a broad range of fields, it is typically only theoreticians that say "experiments have shown". This fits better to ACS Catalysis I think. 
1 with the order of the experimental kinetic data (cis-DCE $<$ trans-DCE $<$ VC). Quantitatively, the

2 relationships between the experimental rate constant $(\log \mathrm{k})$ at different $\mathrm{PH}-\mathrm{pH}$ values $(\mathrm{p} \mathrm{PH}=7$,

38 and 9) and PA of the less-chlorinated ethylenes reveal significant correlations between both

4 properties $\left(\log \mathrm{k}_{\mathrm{PH}} \underline{\mathrm{k}}_{\underline{\mathrm{H}}=7}=0.22 \mathrm{PA}+5.72, r^{2}=0.986 ; \log \mathrm{k}_{\mathrm{PH}} \underline{\mathrm{k}}_{\mathrm{pH}}=8=0.20 \mathrm{PA}+5.87, r^{2}=0.994\right.$;

$\left.5 \log \mathrm{k}_{\mathrm{PH}} \underline{\mathrm{k}}_{\mathrm{pH}}=9=0.20 \mathrm{PA}+6.04, r^{2}=0.997\right)$. Therefore, $\mathrm{PA}$ auld beis a good probe for the kinetic

6 information in the nucleophilic addition pathway with simultaneous protonation for cob(I)alamin-

7 mediated halogenated compounds.

8

9 Table 5. Computed Aqueous-Phase Standard Reduction Potentials ( $E^{0}$ ) (V, vs. SCE) and Vertical

Electron Affinities (VEA) (kcal/mol) for the Base-off and Base-on Forms of Ethylcobalamin

\begin{tabular}{|c|c|c|c|c|c|c|}
\hline & Base-off & $\mathbf{E}^{0}$ & VEA & Base-on & $\mathbf{E}^{0}$ & VEA \\
\hline $\begin{array}{c}\text { dichloroethyl } \\
\text { cobalamin }\end{array}$ & & / & 70.8 & & -1.19 & 64.8 \\
\hline $\begin{array}{l}\text { chloroethyl } \\
\text { cobalamin }\end{array}$ & & / & 65.9 & & -1.24 & 60.4 \\
\hline & & & & & & \\
\hline
\end{tabular}

11

12

13

14

15

16

17

18

In conclusion, the computations provide support for the mechanistic routes and indicate a distinct type of "on/off switch" occurring during cobalamin-mediated reductive dehalogenation of the less-chlorinated ethylenes of the nucleophilic addition pathway: the The initial step is the addition of the "base-off" cob(I)alamin to the less-chlorinated ethylenes with simultaneous protonation $_{\underline{-} ;}$ Tthen the formed base-off form of dichloro- and chloro-ethylcobalamin eould $\underline{\text { can }}$ produce the dehalogenation products directly with formation of "base-on" cob(II)alamin under the reductive reaction conditions (see simplified sketch in Scheme 5). 
1
Scheme 5. The Proposed Reaction Pathway for Cobalamin-Mediated Reductive Dehalogenation of cis-DCE, trans-DCE and $\mathrm{VC}^{a}$

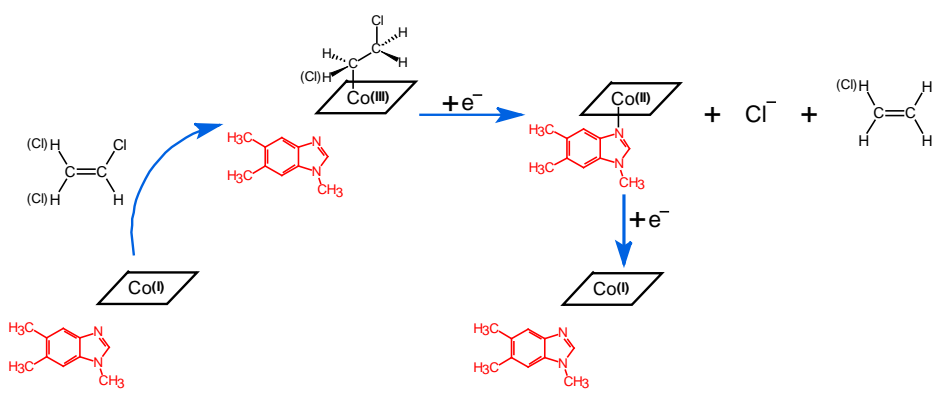

${ }^{a}$ Mulliken charge of dissociated $\mathrm{Cl}$ changes from $0.01 \sim 0.04$ in the reactants, to $0.08 \sim 0.05$ in base - 0 ff

dichloroethylcob(II)alamin, and to -1.0 in in the product complex; Mulliken charge of $\mathrm{CH}_{2} \mathrm{Cl}(\mathrm{H})$ fragment changes from $-0.04 \sim 0.01$ in the reactants, to $-0.17 \sim-0.08$ in the base-off tri-/di-chlorovinylcob(III)alamin. $\underline{s}$ can be found in Supporting Information.

\section{Electronic Structure GharacteristiesAnalysis.}

The unique nature of the $\mathrm{C}-\mathrm{Co}-\mathrm{N}$ bonding in cobalamin, with the competing $\sigma$ and $\pi$ effectss, has continued to beis an important mechanistic subject. Figure 5 shows the importantly relevant frontier molecular orbitals during the reductive processes of chlorinated vinylcobalamins $\_$, while the relevant frontier molecular orbitals for chlorinated ethylcobalamins are shown in Figure S2 in the Supporting Information). As shown in Figure 5 (a), the lowest unoccupied molecular orbitals (LUMOs) of base-off tri- and di-chlorovinyl cob(III)alamins are largely associated with the $\sigma_{\mathrm{Co}-}$ $\mathrm{Ca}{ }^{*}$ orbital, whereas base-off non-chlorovinyl cob(III)alamins have LUMOs mainly coinciding with the corrin macrocycle $\pi^{*}$ orbital, and the LUMO of base-off mono-chlorovinyl cob(III)alamin is mixed corrin macrocycle $\pi^{*}$ (major) and $\sigma_{\mathrm{Co}-\mathrm{C} \alpha} *$ (minor) orbital. Interestingly, the mixed
Commented [KPK29]: Check if ok and reference Table

Formatted: Indent: First line: $0,85 \mathrm{~cm}$

Formatted: First line: $0 \mathrm{ch}$ 
1 character for of the LUMOs of base-off mono-chlorovinyl cob(III)alamin resembles a transition

2 between LUMOs of base-off tri/di-chlorovinyl and non-chlorovinyl cob(III)alamins. The

3 significant difference in LUMO character is mainly due to the fact that the nitrogen atoms of the corrin ring of cobalamin are more electron-rich than the mono- and non-chlorinated ethylene 5 fragments (Mulliken charge: $-0.25 \sim$ to -0.17 ) compared with the tri- and di-chlorovinyl ethylene 6 fragments (Mulliken charge: $-0.38 \sim$ to -0.33 ), so that the corrin ring has larger overlap with the

7 relevant d-orbital in Co than with the $\mathrm{C}_{\alpha}$ atom in the ethylene fragment resulting in dominant $\pi^{*}$ 8 orbital for LUMOs of mono- and non-chlorinated cob(III)alamins (ELUMO: $-5.05 \sim$ to $-5.10 \mathrm{eV}$ ).

9 By contrast, the strong inductive effect of tri- and di-chlorinated ethylene fragment withdraws electron density from the Co center to reduce the effective nuclear charge of the metal ion, thereby lowering the energies of $\mathrm{Co} \mathrm{d}_{\mathrm{z}}^{2}$ orbitals and undergoing a large stabilization of LUMOs on the $\sigma_{\mathrm{Co}-}$ $12 \mathrm{Ca}^{*}$ orbital for base-off tri- and di-chlorovinyl cob(III)alamins (ELUMO: $-5.66 \sim$ to $-5.38 \mathrm{eV}$ ).

13 Generally speaking, the contribution of electron-withdrawing inductive effects from more than or

14 equal to twotwo or more electronegative chlorine atoms is able tocan lower the LUMOs of base-

15 off chlorinated vinylcobalamins, thus producing the corresponding lower $\mathrm{E}^{0}$ values shown in

\section{Table 4.}

These LUMOs of base-off chlorinated vinylcob(III)alamins are initially occupied upon oneelectron reduction to produce the corresponding single occupied molecular orbitals (SOMOs). As shown in Figure 5 (b), these SOMOs remain the same as the localization of their precursor LUMOsunchanged as reflected also infrom the spin densities $(\rho)$ of , that such values are 0.98_ $\sim 0.99$ for SOMOs on the $\sigma_{\mathrm{Co}-\mathrm{Ca}}{ }^{*}$ orbital of tri- and di-chlorovinyl cob(II)alamins-; and are 22 0.87_ 0.88 for the corrin macrocycle $\pi^{*}$ erbital of mono- and non-chlorinated

Commented [KPK30]: ?

Higher potentials imply easier to reduce $=$ lower LUMO energy. Please check 
1 macrocycle $\pi^{*}$ orbital of base-on cob(II)alamins:- particularly tithe SOMO localization changes

2 from $\sigma_{\mathrm{Co}-\mathrm{Ca}} *$ orbital-like $(\rho=0.98)$ in the base-off dichlorovinylcobalamin to corrin $\pi *$ orbital-like

3 ( $\rho=0.88)$ in the base-on species. The reason for this major electronic structure change from base-

4 off to base-on dichlorovinylcobalamin is that an additional strong $\sigma$-antibonding between Co and

5 the DMB base in the base-on species leads to a considerable destabilization of the $\sigma_{\mathrm{Co}-\mathrm{C} \alpha}{ }^{*}$ orbital,

6 thus resulting in SOMO with considerable corrin $\pi$ orbital character. However, the strong

7 withdrawing inductive effect from of the three chlorine atoms in base-on trichlorovinylcobalamin

8 is able to-cancels out the $\sigma$-donating effect from theof DMB base-th $f$ ough still reducing the

9 effective nuclear charge of Co atom to lower the energy of its $\mathrm{d}_{\mathrm{z}}^{2}$ orbital, thereby retaining SOMO

10 localization on the $\sigma_{\mathrm{Co}-\mathrm{C} \alpha}$ * orbital and repelling the DMB base. Interestingly, the distant DMB base

11 in base-on trichlorovinylcobalamin shows weak Van der Waals attraction to further lower the 12 SOMO $\sigma_{\mathrm{Co}-\mathrm{Ca}}{ }^{*}$ orbital, as reflected in comparison of SOMO energies of base-off trichlorovinylcobalamin $\left(\mathrm{E}_{\mathrm{SOMO}}=-2.92 \mathrm{eV}\right)$ and base-on trichlorovinylcobalamin $\left(\mathrm{E}_{\mathrm{SOMO}}=-3.07\right.$

$14 \mathrm{eV})$. 


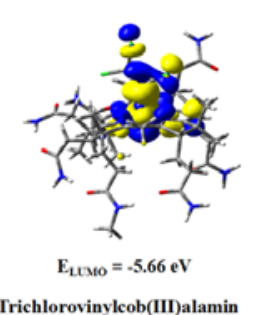

Trichlorovinylcob(III)alamin
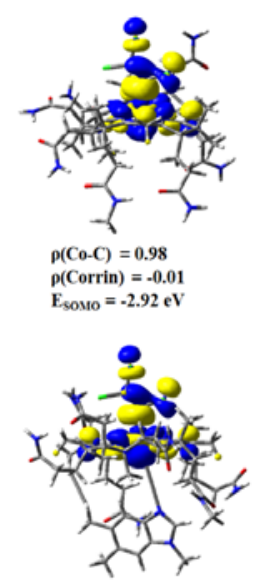

$\rho(\mathrm{Co}-\mathrm{C})=0.99$

$\rho($ Corrin $)=-0.02$
$\mathrm{E}_{\text {sovo }}=-3.07 \mathrm{eV}$

Trichlorovinylcob(II)alamin

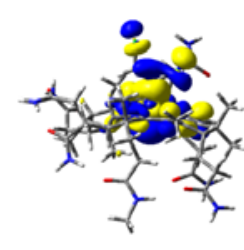

$E_{\text {LบMO }}=-5.38 \mathrm{eV}$

Dichlorovinyleob(III)alamin
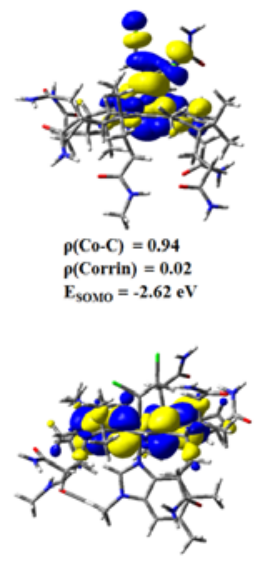

$\rho(\mathrm{Co}-\mathrm{C})=0.05$

$p($ Corrin $)=0.88$

$\mathrm{E}_{\text {SOM⿻ }}=-2.29 \mathrm{eV}$

Dichlorovinylcob(II)alamin

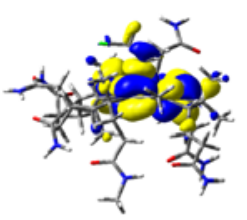

$\mathrm{E}_{\text {นับ }}=-5.10 \mathrm{eV}$

Chlorovinylcob(III)alamin

(a)
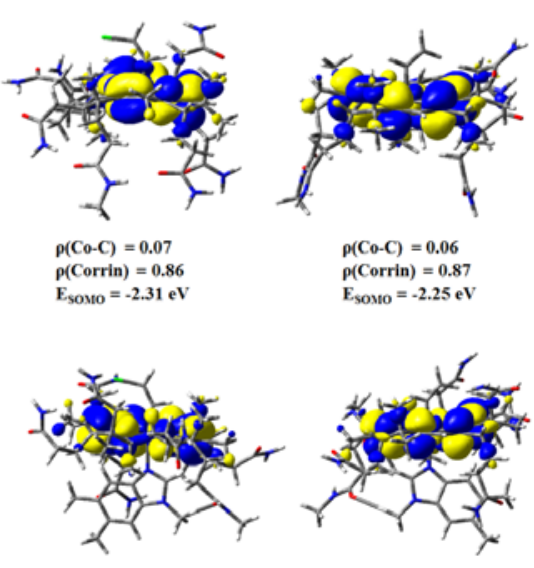

$\rho(\mathrm{Co}-\mathrm{C})=0.05$
$\rho($ Corrin $)=0.88$ $\rho($ Corrin $)=0.88$
$E_{\text {รомо }}=-2.18 \mathrm{eV}$

(b)

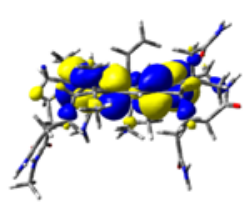

Vinylcob(III)alamin

$\rho(\mathrm{C} 0-\mathrm{C})=0.06$ $p($ Corrin $)=0.88$ $E_{\text {SOMO }}=-2.13 \mathrm{eV}$

Vinylcob(II)alamin
$E_{\text {LIMO }}=-5.05 \mathrm{eV}$ for Co-C Bond [ $\rho($ Co-C)] and Corrin Macrocycle $[\rho($ Corrin)].
Commented [KPK31]: Please check if all figure captions should have capitalized letters

\section{Isotope Effects}

Formatted: Indent: First line: $0,85 \mathrm{~cm}$ 
11

Table 6 summarizes the calculated average carbon KIE (KIE $\mathrm{K}_{\mathrm{C}}$ ) values during the inner-spherenucleophilic substitution pathway for cobalamin-mediated chloroethylenes, together with the experimental $\varepsilon_{\text {bulkC }}$ as well as the compound average carbon AKIE (AKIEC) obtained from $\varepsilon_{\text {bulkC }}$ according to eq 3 . The similarity of the experimental $\mathrm{AKIE}_{\mathrm{C}}$ values with and computational $\mathrm{KIE}_{\mathrm{C}}$ values confirm that cobalamin-mediated PCE and TCE dehalogenation proceeds through the nucleophilic substitution pathway. However, the much larger experimental AKIEc values than the

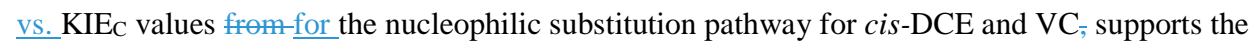
nucleophilic addition of cob(I)alamin to one of the carbon atoms of these chloroethylenes and simultaneous protonation of the other carbon atom, because only the concerted reactions could increase the kinetic isotope effects to the most full extent.

Table 6. Average Calculated Carbon Kinetic Isotope Effects $\left(\mathrm{KIE}_{\mathrm{C}}\right)$ on the Inner-sphere Nucleophilic Substitution Pathway for Cobalamin-mediated Chloroethylenes, as well as the Experimental Carbon Bulk Isotope Fractionation Factors ( $\varepsilon_{\text {bulkc }}$ ) and the Compound Average Carbon Apparent Kinetic Isotope Effect (AKIEc)

\begin{tabular}{c|ccccc}
\hline & PCE & TCE & cis-DCE & trans-DCE & VC \\
\hline KIEC & 1.028 & 1.032 & 1.026 & 1.030 & 1.027 \\
$\boldsymbol{\varepsilon}_{\text {bulkC }}$ & $-15.8 \%$ o & $-16.1 \%$ o & $-25.5 \%$ o & $/$ & $-31.1 \%$ o \\
AKIE $_{\text {C }}$ & 1.033 & 1.033 & 1.054 & $/$ & 1.066 \\
\hline
\end{tabular}

16

Most previous work has focused on stable carbon isotopes to study the transformation process 18 of organic pollutants. However, chlorine also-has high-major relevance for as constituent of many 19 pollutingenvironmental compounds. In practice, only a few chlorine isotope analyses have been 20 performed to investigate the transformation of compounds, and the firstly reported chlorine bulk 21 isotope fractionation factor for cobalamin-mediated chloroethylene is-was $-4.0 \%$ o for TCE, ${ }^{9}$ which 
1 can be converted into $\mathrm{AKIE}_{\mathrm{Cl}}$ of $\sim 1.012$ by eq 3 . The calculated average chlorine KIE for

2 cobalamin-mediated TCE in the inner-sphere nucleophilic substitution pathway is 1.009 , quite

3 close to the experimental AKIE $\mathrm{Cl}$.

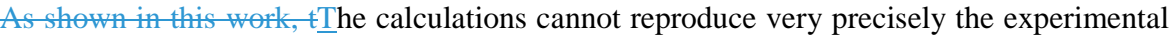

5 data in this instance, since the latter may be masked. Dual element isotope analysis has attracted

6 considerable interest, the advantage of which is that different mechanisms may be discerned simply by correlating the isotope fractionation factor $(\varepsilon)$ ratios for the two elements. Herein, we

8 extend the dual element isotope analysis $ө$ nly-based only on experimental data inte a new manner

9 for comparison between computations and experiments through-by correlating the ratios of $\varepsilon$ or

10 KIE for the two elements. Taking As an example, we consider the reaction of cobalamin-mediated

11 TCE with available dual element isotopes-as an example: the-The reverse eq 3 yields the

12 computational $\varepsilon_{\mathrm{C}}$ of $-15.5 \%$ and $\varepsilon_{\mathrm{Cl}}$ of $-3.0 \% \%_{\overline{5}}$; thus the ratio of computational $\varepsilon_{\mathrm{C}}$ to $\varepsilon_{\mathrm{Cl}}$ in the

13 nucleophilic substitution pathway is calculated to be $5.1: 1.0$, while the ratio of experimental $\varepsilon_{\mathrm{C}}$

$14(-16.1 \%)$ to $\varepsilon_{\mathrm{Cl}}(-4.0 \%)$ is $4.0: 1.0$, so there is some degree ofimplying some difference between

15 computations and experiments based on the correlating ratio of $\varepsilon_{.} ;$In the meanwhileMeanwhile,

16 the calculated ratio of $\mathrm{AKIE}_{\mathrm{C}}$ to $\mathrm{AKIE}_{\mathrm{Cl}}$ is 1.02 - while the ratio of computational $\mathrm{KIE}_{\mathrm{C}}$ to $\mathrm{KIE}_{\mathrm{Cl}}$ in

17 the nucleophilic substitution pathway is 1.02 as well. Furthermore, the latest reported experimental work concerning combined carbon and chlorine isotope analysis during the reductive dehalogenation of TCE by cobalamin provides an $\varepsilon_{C}$ value of $-15.0 \%$ o $(\mathrm{AKIE}=1.031)$ and an $\varepsilon_{\mathrm{Cl}}$

20 value of $-3.2 \%$ o $(\mathrm{AKIE}=1.010),{ }^{31}$ which can be converted into $\mathrm{AKIE} \mathrm{E}_{\mathrm{C}} / \mathrm{AKIE} \mathrm{Cl}$ of 1.02 again,

21 although there is some difference betweenthe two previous studies for experimental $\varepsilon_{c}$-and $\varepsilon_{\mathrm{Cl}}$

22 valuesdiffer somewhat. Since-With the most plausible nucleophilic substitution mechanism for

23 cobalamin-mediated TCE is outlined above, the comparison between correlating ratios of KIE for 
1 the two elements may provides a new probe to detect the reaction mechanism. This approach holds

2 promise to bridge a gap between computations and experiments, because various factors mask the

3 AKIEs of both elements to the same extent so that correlating ratios of KIE for the two elements remain the same.

Previous studies have indicated the _variability variable in isotope fractionation of PCE and TCE by a variety ofdifferent microorganisms ${ }^{81}$ probably due to the complex enzymatic environment for of the dehalogenating strain - thus -Because of this, the elucidation of biological

dehalogenation mechanisms may be hampered by the variability in isotope fractionation. In future work, the reaction mechanisms of the biological dehalogenation eould -is envisioned to be diagnosed potentially by quantum mechanical/molecular mechanical (QM/MM) or cluster modelling to simulate the enzymatic environment in combination with the-our new proposed method of relating calculated $\mathrm{KIE}_{\mathrm{C}} / \mathrm{KIE}_{\mathrm{Cl}}{ }_{s}$ and experimental AKIEC/AKIE $\mathrm{Cl}$.

\section{Conclusions.}

This work shows how computational chemistry closes some key unsolved research gaps for ${ }^{4}$ relating to ${ }_{2}$ cobalamin-mediated reduction of chloroethylenes by distinguishing different mechanisms (Scheme 2). To this end, we have developed some useful quantitative methods that rationalize reactivity by:-(i) serving as screening tools for predicting the reductive dehalogenation reactivity in of a given mechanism (e.g. electron affinity for electron transfer, electrophilic index for nucleophilic substitution, and proton affinity for nucleophilic addition); (ii) providing standard reduction potentials $\left(E^{0}\right)$ of formed chlorinated-cobalamins as one an important parameter for determining the feasibility of the inner-sphere pathway; (iii) offering suggesting the calculated $K I E_{C} / K I E_{C l}$ vs experimental $A K I E_{C} / A K I E_{C l}$ as a probe for diagnosing the overall reaction mechanism. Thus, these quantitative methods may be useful for in determination determining of the environmental fate and development of ing remediation pathways of halogenated organic pollutants.
Formatted: Font: Times New Roman

Formatted: Font: $12 \mathrm{pt}$

Formatted: Indent: First line: $0,85 \mathrm{~cm}$

Formatted: Font: (Default) Times New Roman, 12 pt

Formatted: Normal, First line: $0 \mathrm{ch}$, Line spacing: 1,5 lines

Formatted: Font: (Default) Times New Roman, 12 pt

Formatted: Font: (Default) Times New Roman, 12 pt

Formatted: Font: (Default) Times New Roman, 12 pt

Formatted: Font: (Default) Times New Roman, 12 pt

Formatted: Font: (Default) Times New Roman, $12 \mathrm{pt}$

Formatted: Font: (Default) Times New Roman, 12 pt

Formatted: Font: (Default) Times New Roman, 12 pt

Formatted: Font: (Default) Times New Roman, 12 pt

Commented [KPK32]: Of all reaction types equally well? perhaps specify

Formatted: Font: (Default) Times New Roman, 12 pt Formatted: Font: (Default) Times New Roman, 12 pt Formatted: Font: (Default) Times New Roman, 12 pt Formatted: Font: (Default) Times New Roman, 12 pt Formatted: Font: (Default) Times New Roman, 12 pt Formatted: Font: Times New Roman 
Recently, Payne et al. proposed a third type of mechanismn alternative route, with the cobalamin of reductive dehalogenase able to abstract bromide from 2,6-dibromophenol with formation of a $\mathrm{Co}-\mathrm{Br}$ bond, consequently leading to a $\mathrm{C}-\mathrm{Br}$ bond cleavage concomitant with protonation of the leaving group by nearby residue Tyr426. ${ }^{82}$ At the same time, Bommer et al. further emphasized the role of strictly conserved Tyr246 in reductive dehalogenase pointing with its phenolic group toward carbon to donate the proton to neutralize the dichlorovinyl anion formed upon reaction of TCE with cobalamin cofactor. ${ }^{83}$ The more detailed reaction mechanism of the new proposed dehalogenation mode was computationally elucidated by Liao et al. ${ }^{84-85}$ This new paradigm implies that the repertoire of reductive dehalogenation originating from cobalamin in dehalogenase is even more diverse than previously anticipated, which may guide further modification strategies for cobalamin to mimic the enzyme behavior in in vitro reductive dehalogenations. Together with these recent mechanistic findings, our work spans the so far known possible reactivity space of cobalamin in degradation of halogenated compounds, although we expect that further studies are needed to define the relevance of each reaction type to specific conditions and environments.

\section{ASSOCIATED CONTENT}

Supporting Information. Full citation for reference 70; estimation of activation barriers for electron transfer processes by Marcus theory; computed aqueous-phase standard reduction potentials of vinyl radicals; optimized geometries of $\mathrm{S}_{\mathrm{N}} 2$ transition-state of cobalamin-mediated dehalogenation of chloroethylenes; frontier molecular orbitals for less-chlorinated ethylcobalamins; experimental rate constants for reaction of less-chlorinated ethylcobalamins with 
cob(I)alamin; energies for all molecular species; Mulliken charges and spin densities; intrinsic

2 reaction coordinate (IRC) for verifying transition states; geometrical comparison between-of

$3 \mathrm{PBE} / \mathrm{BSI}$ optimized structures in the gas phase and PBE-D3-CPCM/BSI optimized structures;

4 final one-electron symbolic density matrix of complete cob(I)alamin from CASSCF calculations;

5 eartesian-Cartesian coordinates of all molecular structures-diseussed in this ork. This material is

6 available free of charge via the Internet at http://pubs.acs.org.

7

\section{AUTHOR INFORMATION}

9 Corresponding Author

10 *(L.J.) E-mail: jilienv@zju.edu.cn

11 *(K.P.K.) E-mail: kpj@kemi.dtu.dk

12 *(P.P.) E-mail: piotr.paneth@p.lodz.pl

13 Notes

14 The authors declare no competing financial interest.

15

16

17

18

19

20

\section{ACKNOWLEDGMENT}

This work was supported by the National Natural Science Foundation of China (21677125). The China National Supercomputing Center in Shenzhen is acknowledged for providing the Gaussian 09 package and the high-performance computing clusters. 


\section{ABBREVIATIONS}

DFT, density functional theory; DMB, 5,6-dimethylbenzimidazole; PCE, perchloroethylene; TCE, trichloroethylene; cis-DCE, cis-1,2-dichloroethylene; trans-DCE, trans-1,2-dichloroethylene; VC, vinyl chloride; IRC, intrinsic reaction coordinate; CSIA, compound specific isotope analysis; KIEs, kinetic isotope effects; AKIEs, apparent kinetic isotope effects; PBE, Perdew-Burke-Ernzerhof; ZPE, zero-point energy correction; CPCM, COSMO continuum-solvation model; SCE, standard calomel electrode; VEA, vertical electron affinities; HSAB, hard and soft acids and bases; HOMO, highest occupied molecular orbital; LUMO, lowest unoccupied molecular orbital; LFER, linear free energy relationship; PA, proton affinity.

\section{REFERENCES}

(1) Fenner, K.; Canonica, S.; Wackett, L. P.; Elsner, M. Science 2013, 341, 752-758.

(2) Schwarzenbach, R. P.; Egli, T.; Hofstetter, T. B.; von Gunten, U.; Wehrli, B. Annu. Rev. Environ. Resour. 2010, 35, 109-136.

(3) Alonso, F.; Beletskaya, I. P.; Yus, M. Chem. Rev. 2002, 102, 4009-4091.

(4) Leys, D.; Adrian, L.; Smidt, H. Philos. Trans. R. Soc. Lond. B Biol. Sci. 2013, 368, 20120316.

(5) Smidt, H.; de Vos, W. M. Annu. Rev. Microbiol. 2004, 58, 43-73.

(6) Stich, T. A.; Brooks, A. J.; Buan, N. R.; Brunold, T. C. J. Am. Chem. Soc. 2003, 125, 58975914. 
(7) Kozlowski, P. M.; Garabato, B. D.; Lodowski, P.; Jaworska, M. Dalton Trans. 2016, 45, $2 \quad 4457-4470$.

(8) Liptak, M. D.; Brunold, T. C. J. Am. Chem. Soc. 2006, 128, 9144-9156.

(9) Cretnik, S.; Thoreson, K. A.; Bernstein, A.; Ebert, K.; Buchner, D.; Laskov, C.; Haderlein,

5 S.; Shouakar-Stash, O.; Kliegman, S.; McNeill, K.; Elsner, M. Environ. Sci. Technol. 2013, 47, $6 \quad 6855-6863$.

7 (10) Sorel, D.; Lesage, S.; Brown, S.; Millar, K. Ground Water Monit. Rem. 2001, 21, 140-148.

(11) Kliegman, S.; McNeill, K. Dalton Trans. 2008, 4191-4201.

(12) Giedyk, M.; Goliszewska, K.; Gryko, D. Chem. Soc. Rev. 2015, 44, 3391-3404.

(13) Zhou, D. L.; Njue, C. K.; Rusling, J. F. J. Am. Chem. Soc. 1999, 121, 2909-2914.

(14) Elsner, M.; Hofstetter, T. B., Current Perspectives on the Mechanisms of 12 Chlorohydrocarbon Degradation in Subsurface Environments: Insight from Kinetics, Product 13 Formation, Probe Molecules, and Isotope Fractionation. In Aquatic Redox Chemistry, Tratnyek, P. G.; Grundl, T. J.; Haderlein, S. B., Eds. 2011; Vol. 1071, pp 407-439.

(15) Perlinger, J. A.; Buschmann, J.; Angst, W.; Schwarzenbach, R. P. Environ. Sci. Technol. 1998, 32, 2431-2437.

(16) Song, H.; Carraway, E. R. Environ. Sci. Technol. 2005, 39, 6237-6245.

(17) Arnold, W. A.; Ball, W. P.; Roberts, A. L. J. Contam. Hydrol. 1999, 40, 183-200.

19

(18) Lexa, D.; Saveant, J. M. Acc. Chem. Res. 1983, 16, 235-243. 
(19) Jensen, K. P. J. Phys. Chem. B 2005, 109, 10505-10512.

(20) Gantzer, C. J.; Wackett, L. P. Environ. Sci. Technol. 1991, 25, 715-722.

(21) Glod, G.; Angst, W.; Holliger, C.; Schwarzenbach, R. P. Environ. Sci. Technol. 1997, 31, 253-260.

5 (22) Glod, G.; Brodmann, U.; Angst, W.; Holliger, C.; Schwarzenbach, R. P. Environ. Sci. 6 Technol. 1997, 31, 3154-3160.

(23) Follett, A. D.; McNeill, K. J. Am. Chem. Soc. 2005, 127, 844-845.

8

(24) Costentin, C.; Robert, M.; Saveant, J. M. J. Am. Chem. Soc. 2005, 127, 12154-12155.

9

(25) Lesage, S.; Brown, S.; Millar, K. Environ. Sci. Technol. 1998, 32, 2264-2272.

10

(26) Slater, G. F.; Lollar, B. S.; Lesage, S.; Brown, S. Ground Water Monit. Rem. 2003, 23, 5967.

12

(27) Slater, G. F.; Lollar, B. S.; Sleep, B. E.; Edwards, E. A. Environ. Sci. Technol. 2001, 35, $13 \quad 901-907$.

(28) Hunkeler, D.; Aravena, R.; Cox, E. Environ. Sci. Technol. 2002, 36, 3378-3384.

(29) Nijenhuis, I.; Andert, J.; Beck, K.; Kastner, M.; Diekert, G.; Richnow, H. H. Appl. Environ.

Microbiol. 2005, 71, 3413-3419.

17 (30) Cichocka, D.; Siegert, M.; Imfeld, G.; Andert, J.; Beck, K.; Diekert, G.; Richnow, H. H.;

Nijenhuis, I. FEMS Microbiol. Ecol. 2007, 62, 98-107. 
2 Nijenhuis, I. Environ. Sci. Technol. 2014, 48, 11837-11845.

(32) Paneth, P. Acc. Chem. Res. 2003, 36, 120-126.

(33) Elsner, M.; Zwank, L.; Hunkeler, D.; Schwarzenbach, R. P. Environ. Sci. Technol. 2005, $5 \quad 39,6896-6916$.

(34) Santoro, S.; Kalek, M.; Huang, G. P.; Himo, F. Acc. Chem. Res. 2016, 49, 1006-1018.

(35) Ji, L.; Schuurmann, G. Angew. Chem. Int. Ed. 2013, 52, 744-748.

(36) Kumar, N.; Kozlowski, P. M. J. Phys. Chem. B 2013, 117, 16044-16057.

(37) Jensen, K. P.; Ryde, U. J. Am. Chem. Soc. 2005, 127, 9117-9128.

(38) Quesne, M. G.; Senthilnathan, D.; Singh, D.; Kumar, D.; Maldivi, P.; Sorokin, A. B.; de

(40) Zhang, J.; Ji, L.; Liu, W. P. Chem. Res. Toxicol. 2015, 28, 1522-1531.

(41) Leitch, J. A.; Wilson, P. B.; McMullin, C. L.; Mahon, M. F.; Bhonoah, Y.; Williams, I. H.;

16 Frost, C. G. ACS Catal. 2016, 6, 5520-5529.

(42) Swiderek, K.; Tunon, I.; Marti, S.; Moliner, V. ACS Catal. 2015, 5, 1172-1185.

(43) Swiderek, K.; Marti, S.; Moliner, V. ACS Catal. 2014, 4, 426-434.

(44) Pratt, D. A.; van der Donk, W. A. J. Am. Chem. Soc. 2005, 127, 384-396. 
(45) Pratt, D. A.; van der Donk, W. A. Chem. Commun. 2006, 558-560.

(46) Nonnenberg, C.; van der Donk, W. A.; Zipse, H. J. Phys. Chem. A 2002, 106, 8708-8715.

(47) Buhl, M.; Golubnychiy, V. Organometallics 2007, 26, 6213-6218.

(48) Follett, A. D.; McNabb, K. A.; Peterson, A. A.; Scanlon, J. D.; Cramer, C. J.; McNeill, K. Inorg. Chem. 2007, 46, 1645-1654.

(49) Vosko, S. H.; Wilk, L.; Nusair, M. Can. J. Phys. 1980, 58, 1200-1211.

(50) Perdew, J. P.; Burke, K.; Ernzerhof, M. Phys. Rev. Lett. 1996, 77, 3865-3868.

(51) Schafer, A.; Huber, C.; Ahlrichs, R. J. Chem. Phys. 1994, 100, 5829-5835.

(52) Hehre, W. J.; Ditchfield, R.; Pople, J. A. J. Chem. Phys. 1972, 56, 2257-+.

(53) Giorgetti, M.; Ascone, I.; Berrettoni, M.; Conti, P.; Zamponi, S.; Marassi, R. J. Biol. Inorg. Chem. 2000, 5, 156-166.

(54) Wirt, M. D.; Sagi, I.; Chance, M. R. Biophys. J. 1992, 63, 412-417.

(55) Kepp, K. P. J. Phys. Chem. A 2014, 118, 7104-7117.

(56) Grimme, S. J. Comput. Chem. 2006, 27, 1787-1799.

(57) Stich, T. A.; Buan, N. R.; Brunold, T. C. J. Am. Chem. Soc. 2004, 126, 9735-9749.

(58) Kumar, N.; Alfonso-Prieto, M.; Rovira, C.; Lodowski, P.; Jaworska, M.; Kozlowski, P. M. J Chem Theory Comput 2011, 7, 1541-1551.

(59) Jensen, K. P.; Ryde, U. Coord. Chem. Rev. 2009, 253, 769-778. 
(60) Kumar, M.; Galezowski, W.; Kozlowski, P. M. Int. J. Quantum Chem 2013, 113, 479-488.

(61) Frisch, M. J.; Pople, J. A.; Binkley, J. S. J. Chem. Phys. 1984, 80, 3265-3269.

(62) Pearson, R. G. Coord. Chem. Rev. 1990, 100, 403-425.

(63) LoPachin, R. M.; Gavin, T.; DeCaprio, A.; Barber, D. S. Chem. Res. Toxicol. 2012, 25, 239-251.

(64) Zhang, J.; Wang, C.; Ji, L.; Liu, W. Chem. Res. Toxicol. 2016, 29, 841-850.

(65) Wolfsberg, M.; Van Hook, A.; Paneth, P., Isotope Effects in the Chemical, Geological and Bio Sciences. Springer: London, 2010.

(66) Wilson, P. B.; Williams, I. H. Angew. Chem. Int. Ed. 2016, 55, 3192-3195.

(67) Swiderek, K.; Tunon, I.; Marti, S.; Moliner, V.; Bertran, J. J. Am. Chem. Soc. 2013, 135, 8708-8719.

(68) Anisimov, V.; Paneth, P. J. Math. Chem. 1999, 26, 75-86.

(69) Paneth, P. Environ. Chem. 2012, 9, 67-68.

(70) Frisch, M. J. et. al., Gaussian 09, revision D.01, Gaussian, Inc.: Wallingford, CT, 2013. see Supporting Information.

(71) Rizzato, S.; Berges, J.; Mason, S. A.; Albinati, A.; Kozelka, J. Angew. Chem. Int. Edit. 2010, 49, 7440-7443.

(72) Kumar, M.; Kozlowski, P. M. Angew. Chem. Int. Edit. 2011, 50, 8702-8705.

(73) Kumar, M.; Kumar, N.; Hirao, H.; Kozlowski, P. M. Inorg. Chem. 2012, 51, 5533-5538. 
(75) Marcus, R. A. Angew. Chem. Int. Ed. 1993, 32, 1111-1121.

(76) Jones, G. O.; Liu, P.; Houk, K. N.; Buchwald, S. L. J. Am. Chem. Soc. 2010, 132, 62056213.

(77) Kumar, S.; Faponle, A. S.; Barman, P.; Vardhaman, A. K.; Sastri, C. V.; Kumar, D.; de 6 Visser, S. P. J. Am. Chem. Soc. 2014, 136, 17102-17115.

7 (78) Lin, C. Y.; Coote, M. L.; Gennaro, A.; Matyjaszewski, K. J. Am. Chem. Soc. 2008, 130, $8 \quad 12762-12774$.

9 (79) Birke, R. L.; Huang, Q.; Spataru, T.; Gosser, D. K., Jr. J. Am. Chem. Soc. 2006, 128, 1922101936

11 (80) Kozlowski, P. M.; Kuta, J.; Galezowski, W. J. Phys. Chem. B 2007, 111, 7638-7645.

(81) Nijenhuis, I.; Richnow, H. H. Curr. Opin. Biotechnol. 2016, 41, 108-113.

(82) Payne, K. A.; Quezada, C. P.; Fisher, K.; Dunstan, M. S.; Collins, F. A.; Sjuts, H.; Levy, 14 C.; Hay, S.; Rigby, S. E.; Leys, D. Nature 2015, 517, 513-516.

15 (83) Bommer, M.; Kunze, C.; Fesseler, J.; Schubert, T.; Diekert, G.; Dobbek, H. Science 2014, 346, 455-458.

17 (84) Liao, R. Z.; Chen, S. L.; Siegbahn, P. E. M. ACS Catal. 2015, 7350-7358.

(85) Liao, R. Z.; Chen, S. L.; Siegbahn, P. E. Chem. - Eur. J. 2016, 22, 12391-12399.

\section{SYNOPSIS}




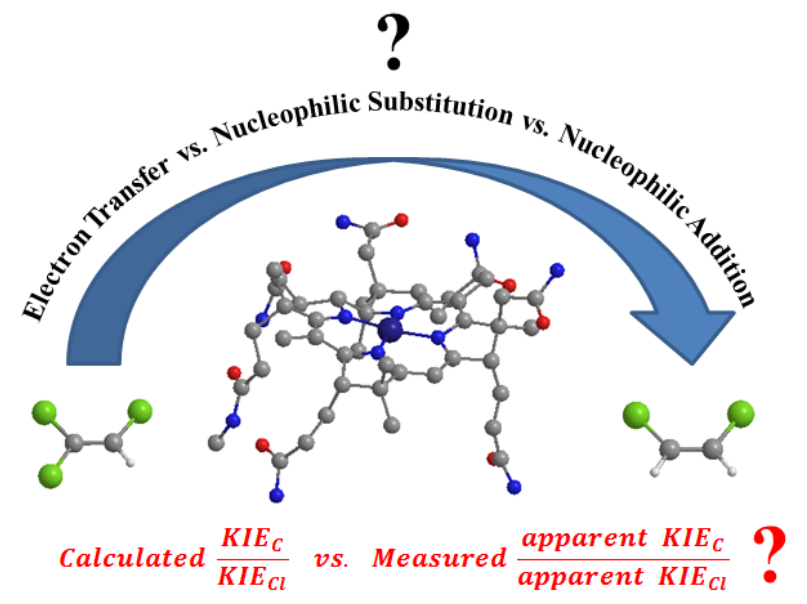

